\title{
DETERMINANTES DE LA PROBABILIDAD DE CIERRE DE NUEVAS EMPRESAS EN BOGOTÁ*
}

\author{
JUAN FELIPE PARRA" \\ COLEGIO DE ESTUDIOS SUPERIORES DE ADMINISTRACIÓN (CESA)- COLOMBIA
}

Recibido/ Received/ Recebido: 11/08/2011 - Aceptado/ Accepted/Aprovado: 01/03/2011

\begin{abstract}
Resumen
El artículo analiza los determinantes de la probabilidad de cerrar una firma nueva en el mercado antes de que alcance sus primeros cinco años de actividades. Se estudian las condiciones macroeconómicas y microeconómicas que experimentaron estas empresas en Bogotá durante su primer lustro. El estudio revela que hay indicios para afirmar que el tamaño óptimo de entrada es el de pequeña y mediana empresa (PYMEs). Entre los principales hallazgos de la investigación están, en primer lugar, que las empresas más proclives a la quiebra prematura son las microempresas, en segundo lugar, para algunas empresas el endeudamiento moderado puede ser útil para apalancarse, pero el alto endeudamiento, finalmente, se verificó que, tanto el sector económico, como la localidad en la que abre sus puertas la nueva empresa, son determinantes en su probabilidad de cerrar antes de los primeros cinco años.
\end{abstract}

Palabras clave: Supervivencia de empresas, modelos probit, nuevas empresas, creación de empresas star ups.

\section{PROBABILITY DETERMINANTS OF NEW ENTERPRISES CLOSURE IN BOGOTÁ}

\begin{abstract}
This article analyzes the determinants of probability of closing a new firm in the market before completing five years of operation. Macroeconomic and microeconomic conditions which were experienced by those firms in Bogotá were studied. The study reveals that it can be affirmed that the optimum size of a firm to enter into the market is small and medium enterprise (SME). Main findings are, in the first place, that the enterprises most likely to premature bankrupt are micro enterprises, in second place, for some enterprises;moderate indebtedness can be useful for leverage, and finally, high indebtedness is determinant for an enterprise closure before completing its fifth year of operation.
\end{abstract}

Keywords: Enterprise survival, probit models, new enterprises, enterprise creation, star ups.

Artículo de investigación científica resultado del proyecto "Determinantes de supervivencia de nuevas empresas", financiado por el CESA - Colegio de Estudios Superiores de Administración.

* Economista de la Universidad del Valle y Magíster en Economía de la Universidad de los Andes. Profesor-Investigador del CESA. Miembro del Grupo de investigación en innovación y gestión empresarial avalado por Colciencias. El autor agradece los comentarios realizados a versiones previas de este documento por parte de los profesores Juan Santiago Correa y Andrés Mora Valencia del CESA y los del evaluador anónimo de la revista. Correo electrónico: jparra@cesa.edu.co 


\title{
DETERMINANTES DA PROBABILIDADE DE FECHAMENTO DOUTRAS FIRMAS EM BOGOTÁ
}

\begin{abstract}
Resumo
O artigo analisa os determinantes da probabilidade de fechamento de uma firma nova no mercado antes de seus primeiros cinco anos de atividades. Estudam-se as condições macroeconômicas e microeconômicas experimentadas por estas empresas, em Bogotá, durante o seu primeiro quinquénio. As evidências achadas indicam que o tamanho ideal da entrada é de pequenas e médias empresas (MPEs). As principais conclusões do inquérito são: em primeiro lugar, as empresas mais suscetíveis a falências prematuras são as micro; em segundo lugar, para algumas empresas a dívida moderada pode ser útil no seu posicionamento. Finalmente, verificamos que tanto o setor econômico como a cidade onde a nova firma inicia actividades são cruciais para suas chances de fechar antes dos primeiros cinco anos.
\end{abstract}

Palavras chave: Sobrevivência de firmas, modelos probit, novas firmas, criação de firmas, star ups.

Parra, J. (2011). Determinantes de la probabilidad de cierre de nuevas empresas en Bogotá. En: Revista de la Facultad de Ciencias Económicas de la Universidad Militar Nueva Granada. rev.fac. cienc.econ, XIX (1).

JEL: L25, C25, M13.

\section{Introducción}

El presente artículo pretende establecer los determinantes de la quiebra prematura en nuevas empresas en la ciudad de Bogotá. Por cuestiones de disponibilidad de la información se escogieron las firmas que iniciaron operaciones entre los años 2004 y 2005 y, dado que se reconoce que el período inicial de las empresas resulta ser el más crítico, se analizaron algunas variables que pudieron afectar el comportamiento de la firma en los primeros cinco años de actividades. Aunque este artículo se podría enmarcar junto con aquellos que aplican modelos de predicción de quiebra para identificar los factores que influyen en el cierre de las firmas, pretende ir más allá del simple análisis de sus indicadores financieros. Por ejemplo, se busca ofrecer algunas luces acerca de la importancia del sector económico en el que se ubican las nuevas firmas, la influencia del tamaño que tienen dichas unidades productivas y su localización dentro de la ciudad.
Todo lo anterior sin dejar de lado el entorno macroeconómico favorable que se presentó en la mayoría de los años del periodo de estudio. De esta manera, aunque no se incluyen dentro de las estimaciones variables macroeconómicas como crecimiento, inflación, desempleo y tasa de cambio, sí se hace un análisis descriptivo de ellas. La metodología usada para cumplir con el objetivo del trabajo corresponde a uno de los modelos de respuesta discreta, específicamente el probit. Este tipo de modelos presenta un buen comportamiento al momento de predecir la probabilidad de que ocurra un evento, en este caso, el cierre ${ }^{1}$ de una firma joven o con pocos años en el mercado.

En este documento se suministra una radiografía de las condiciones macroeconómicas y microeconómicas en las que operaron las empresas de la muestra desde su inicio hasta su cierre o, en caso de continuar en el mercado, hasta el año 2009. Así, se dejan ver algunas alternativas para reducir la pro-

1 Para una mejor redacción y para evitar el uso excesivo de la frase probabilidad de cierre, en ocasiones se usarán, de manera indistinta, las frases probabilidad de fracaso, probabilidad de desaparecer o probabilidad de quiebra. 
babilidad de fracaso en nuevos emprendimientos y se facilitan algunos elementos a tener en cuenta a la hora de considerar la creación de una empresa. Adicionalmente, los resultados obtenidos podrían ser útiles para los encargados de elaborar las políticas de apoyo al emprendimiento, por cuanto despejan algunas dudas con respecto a las características de los sectores en los que se observa mayor posibilidad de éxito.

Este artículo es pionero en el estudio de las nuevas empresas en Colombia, pues la aplicación de modelos de respuesta discreta y el análisis de la probabilidad de cierre se ha hecho previamente, pero sólo para firmas con varios años en el mercado. De esta manera, más allá de los resultados, se plantean hipótesis que pueden resultar de interés para otras investigaciones además de sentarse un precedente relativo a la importancia de tener mejores bases de datos para el análisis de empresas recién creadas.

El artículo presenta en la siguiente sección algunos modelos teóricos asociados al tamaño de la firma, posteriormente se estudian las variables tradicionalmente usadas en otros trabajos similares al aquí propuesto y en seguida se presenta las estadísticas descriptivas y la metodología. Por último se presentan los resultados y las conclusiones.

\section{Modelos teóricos referidos al tamaño de la firma}

El objeto de esta sección no es profundizar en aspectos técnicos de modelación matemática y económica, sino señalar algunas de las características que diferencian las principales tendencias teóricas que estudian la dinámica industrial, entendida como el proceso de entrada y salida de firmas en un mercado. Por esta razón, el lector interesado en profundizar sobre los aspectos matemáticos de cada uno de los modelos, puede hacer referencia a las fuentes originales de los autores que se encuentran citados en esta sección.
El problema de la entrada y salida de firmas al mercado ha sido estudiado por la teoría económica desde principios del siglo pasado. Entre los modelos que analizan la entrada y la salida de empresas en el mercado, uno de los más citados es el de Schumpeter $(1976)^{2}$, quien popularizó el término destrucción creativa. Este término se utilizó para describir la manera como el crecimiento económico responde a un proceso de selección natural del mercado, en el que la entrada de nuevas firmas con mayor eficiencia desplaza a las menos eficientes. En este artículo (Schumpeter, 1976) se señala que el mecanismo por el cual nacen y mueren empresas se puede comparar con un bosque en el que los nuevos árboles acaban por reemplazar a los de más años que ya no pueden mantenerse.

Jovanovic (1982) por su parte, describió el proceso por el cual se produce la rotación de firmas en el mercado a través del modelo de aprendizaje pasivo. Este modelo señala que las firmas, al momento de entrar, no conocen los beneficios que pueden alcanzar, sólo aprenden a medida que transcurre el tiempo y obtienen los ingresos de su actividad. Dada la incertidumbre y a fin de minimizar el riesgo, las nuevas firmas ingresan al mercado con un tamaño pequeño y posteriormente, según los beneficios que obtengan, se podrían expandir, contraer o salir del mercado (López-García \& Puente, 2006). Este modelo llega a la conclusión de que, en la medida en que una firma opera durante más tiempo en el mercado, más experiencia adquiere y más eficiente se vuelve, si la firma deja de ser eficiente sus competidores la desplazarán de su lugar en el mercado. Algunos resultados importantes del artículo de Jovanovic están relacionados con el tamaño de la firma y la concentración de la industria, las cuales parecen estar positivamente correlacionadas con la tasa de retorno.

Asimismo, Jovanovic encontró que la correlación de las tasas de retorno, a través del tiempo, es más alta para firmas grandes en industrias concentradas. La variabilidad de las tasas de retorno aumenta con la concentración del mercado y la alta concentra-

2 Corresponde a una reedición del texto original que data de 1912. 
ción supone elevados márgenes para las grandes empresas pero no para las pequeñas. Otra implicación del modelo es que a medida que los mercados maduran se presentan economías de escala, lo que amplía la brecha de ingresos entre grandes y pequeños (Martínez, 2006).

Un tercer modelo que ha sido bastante referenciado en la literatura de dinámica industrial es el modelo de aprendizaje activo (Ericson \& Pakes, 1995). En este modelo las firmas invierten desde el inicio un volumen significativo de recursos, con esa inversión inicial obtienen un tamaño que les permite incrementar su productividad y, de esta manera, menor probabilidad de desaparecer del mercado. A diferencia del modelo de aprendizaje pasivo, en el modelo de aprendizaje activo la estrategia de entrada de las firmas, en términos de la inversión inicial, se podría denominar "agresiva" y los retornos aleatorios de dicha inversión determinan el éxito de la firma, así se define su expansión, contracción o salida del mercado (Martínez, 2006). En síntesis, al mejorar la dotación inicial, se facilita el proceso de adaptación a las condiciones del mercado y con ello, las nuevas firmas disminuyen su probabilidad de cierre o desaparición prematura.

En resumen, los principales modelos sobre dinámica industrial plantean tres posibles escenarios. El primero de ellos en el que se presenta una rotación de las firmas, de manera que las nuevas firmas son más eficientes y reemplazan paulatinamente a las de más años; un segundo escenario en el que las firmas deciden ingresar al mercado con una estrategia conservadora y su decisión de permanecer es el resultado de los retornos aleatorios a su inversión inicial; y finalmente, un tercer escenario posible es aquel en el que las empresas ingresan al mercado con una estrategia "agresiva", que le garantice desde un principio menores probabilidades de fracasar en el mercado.

El principal objetivo del presente trabajo no es el estudio de la rotación empresarial en Bogotá, sin embargo, la discusión teórica aquí planteada resulta ser, a lo menos, el punto de partida de todo el debate. El objetivo del trabajo, como se ha mencionado antes, es el análisis de los determinantes de la quie- bra prematura de nuevas empresas y la descripción de las condiciones en las que ellas operaron en sus primeros cinco años de actividades. El esbozo de la teoría económica sobre dinámica industrial, que se ha hecho a lo largo de esta sección, ofrece las principales características de los modelos existentes sobre rotación de firmas en un mercado.

Con este marco de referencia, se podrían comparar estos aspectos teóricos con los resultados de las estimaciones acerca de la probabilidad de cierre de nuevas empresas en Bogotá y establecer si existen indicios acerca del modelo que mejor se ajusta al entorno empresarial local. De esta manera, si el modelo de Schumpeter es el más acorde con lo que sucede en Bogotá, se esperaría que las empresas más antiguas y menos eficientes sean las que tiendan a desaparecer. A pesar de su consistencia teórica, este modelo ha sido desvirtuado por diferentes investigaciones que afirman que los primeros años de actividades son los más difíciles (Mata, Geroski \& Portugal, 2003, 3); y que una vez superado este primer momento, la empresa logra consolidarse más fácilmente en el mercado y expandirse.

En consecuencia, las dos alternativas teóricas a comparar con el tejido empresarial bogotano son el modelo de aprendizaje pasivo y el modelo de aprendizaje activo. El modelo de Jovanovic -aprendizaje pasivo-, estaría más cerca de situaciones en las que se evidencie que las nuevas empresas que finalmente logran permanecer en el mercado, son aquellas que ingresan con estrategias conservadoras. Este tipo de firmas podrían asemejarse a unidades productivas de tamaño pequeño y mediano, con niveles de inversión inicial que no sean tan altos como los de las grandes empresas.

Por otra parte, el modelo de aprendizaje activo (Ericson \& Pakes, 1995), podría asociarse con la tendencia a considerar que la menor probabilidad de desaparecer está asociada con un mayor tamaño de la nueva firma y mayores rendimientos. Al respecto, existe abundante literatura que apoya esta tesis al señalar que a mayor tamaño, menos probabilidades de cierre $^{3}$. No obstante, el estudio de estas condiciones

3 Ver Anexo 2 al final del documento. 
iniciales no se ha realizado para las nuevas firmas bogotanas por lo que vale la pena analizar estos elementos y contrastarlos con los datos aquí obtenidos.

\section{Variables tradicionales relacionadas con la supervivencia de la firma}

Adicional al tamaño de la firma existe una infinidad de variables que pueden explicar la probabilidad de cierre. Esa es la conclusión a la que se llega después de realizar la revisión de la literatura sobre el tema, en la que se pueden encontrar diferentes artículos que intentan desentrañar las circunstancias que conllevan al cierre de una firma. Estos artículos generalmente aplican técnicas estadísticas como el análisis discriminante $e^{4}$ o modelos de respuesta cualitativa como el probit o el logit ${ }^{5}$. Entre la literatura revisada también se encontró una buena cantidad de documentos que estudian la probabilidad de cierre de las firmas a través de modelos de duración. Dichos modelos aplican técnicas no paramétricas como la de Kaplan-Meier o semi-paramétricas como el modelo de riesgo proporcional de Cox. A diferencia de los modelos de respuesta cualitativa, los modelos de duración analizan la evolución de las variables en el tiempo.

El objetivo de este artículo es, a través de un análisis estático, presentar algunas características de las firmas que sobreviven en contraste con las que cierran prematuramente. No obstante, el Anexo 1 permite observar los principales hallazgos de algunos artículos que aplican modelos de duración y, además, se presentan esquemáticamente los resultados completos de la literatura revisada.

En relación con los hallazgos de la revisión, se puede afirmar que las variables utilizadas para predecir la quiebra de una empresa, se agrupan en dos tipos: microeconómicas y macroeconómicas. Las variables micro, a su vez, se pueden dividir entre aquellas que están asociadas con la firma y las que tienen relación con el sector industrial al que pertenecen.

Entre las variables microeconómicas asociadas a la firma la de mayor relevancia es el tamaño de la em- presa, ampliamente estudiada en la literatura pues, como se señaló previamente, permite hacer inferencia acerca del modelo teórico subyacente. Otras variables micro usualmente estudiadas en este tipo de artículos son las financieras, como la rentabilidad, el endeudamiento y la liquidez. Por último, en lo que se refiere a las variables microeconómicas asociadas a la firma, existen otras mucho más específicas como la capacidad de innovación, la publicidad, las estrategias de diferenciación de productos, etc. Por razones de disponibilidad de la información, estas últimas no se incluyen dentro del análisis empírico que se presentará más adelante.

Por otra parte, con respecto a las variables microeconómicas asociadas a la industria, a menudo es común encontrar artículos que se interesan por el grado de concentración, es decir, la cuota de mercado que manejan las empresas más grandes de cada sector. Desde esta perspectiva, también se pueden incluir otras variables micro como el carácter tecnológico de la misma, el grado de innovación o la rotación de empresas en el sector.

Aunque estas variables resultan sumamente interesantes, nuevamente la disponibilidad de la información impide incluirlas dentro de las estimaciones. Las que sí se pueden incluir, y que al mismo tiempo resultan de gran interés entre los investigadores (Acts, Armingthon \& Zhang, 2006) son las variables de localización geográfica y el sector económico en el que se ubican las firmas. En síntesis, una revisión exhaustiva de la literatura permite observar que son múltiples las variables que se pueden considerar como los determinantes de la probabilidad de cierre de una firma.

La tabla 1 presenta, de acuerdo con la clasificación hecha hasta aquí, las variables consideradas por algunos de los estudios revisados. Además de las variables micro señaladas y su división en dos grupos, también se presentan variables macroeconómicas como la tasa de crecimiento de la economía, el desempleo, la inflación, la tasa de interés, el tipo de cambio, etc.

\footnotetext{
Un artículo que aplica esta técnica es Rosillo (2002). El autor aplica la metodología propuesta por Altman (1968).

Algunos de ellos se presentan en el Anexo 1.
} 
Tabla 1. Variables microeconómicas y macroeconómicas incluidas en estudios sobre probabilidad de fracaso de empresas. ${ }^{6}$

\begin{tabular}{|c|c|c|}
\hline \multicolumn{2}{|c|}{ Variables microeconómicas } & Variables macroeconómicas \\
\hline Asociadas a la firma & Asociadas a la industria & $\begin{array}{l}\text { Tasa de cambio } \\
\text { (Fajnzylber, Maloney \& Ribeiro, 2001) }\end{array}$ \\
\hline $\begin{array}{l}\text { Tamaño } \\
\text { (Gran mayoría de los autores) }\end{array}$ & $\begin{array}{l}\text { Ciclo de vida } \\
\text { (Agarwal \& Gort, 1999) }\end{array}$ & $\begin{array}{l}\text { Aranceles } \\
\text { (Fajnzylber, Maloney \& Ribeiro, 2001) }\end{array}$ \\
\hline $\begin{array}{l}\text { Inversión en R \& D } \\
\text { (Segarra \& Teruel, 2007) }\end{array}$ & $\begin{array}{l}\text { Intensidad tecnológica } \\
\text { (Segarra \& Teruel, 2007) }\end{array}$ & $\begin{array}{l}\text { Tasa de interés } \\
\text { (Audretsch \& Mahmood, 1995) }\end{array}$ \\
\hline $\begin{array}{l}\text { Capital humano } \\
\text { (Geroski et al., 2003, 2007) }\end{array}$ & $\begin{array}{l}\text { Intensidad del capital } \\
\text { (Audretsch \& Mahmood, 1994) }\end{array}$ & $\begin{array}{l}\text { Nivel de salarios } \\
\text { (Audretsch \& Mahmood, 1995) }\end{array}$ \\
\hline $\begin{array}{l}\text { Publicidad } \\
\text { (Álvarez \& Vergara, 2007) }\end{array}$ & $\begin{array}{l}\text { Concentración } \\
\text { (Geroski et al., 2003, 2007) }\end{array}$ & $\begin{array}{l}\text { Ciclo económico } \\
\text { (Buddelmeyer et al., 2006) }\end{array}$ \\
\hline $\begin{array}{l}\text { Endeudamiento } \\
\text { Martínez, 2005) }\end{array}$ & $\begin{array}{l}\text { Sector económico } \\
\text { (Martínez, 2005) }\end{array}$ & $\begin{array}{l}\text { Penetración de importaciones } \\
\text { (Fajnzylber, Maloney \& Ribeiro, 2001) }\end{array}$ \\
\hline $\begin{array}{l}\text { Rentabilidad } \\
\text { Martínez, 2005) }\end{array}$ & $\begin{array}{l}\text { Grado de innovación } \\
\text { (Audretsch \& Mahmood, 1994) }\end{array}$ & $\begin{array}{l}\text { Coeficiente de exportaciones } \\
\text { (Fajnzylber, Maloney \& Ribeiro, 2001) }\end{array}$ \\
\hline $\begin{array}{l}\text { Liquidez } \\
\text { Martínez, 2005) }\end{array}$ & $\begin{array}{l}\text { Tasa de entrada } \\
\text { (Mata \& Portugal, 1994) }\end{array}$ & $\begin{array}{l}\text { Demanda } \\
\text { (Eslava, Haltiwanger, Kugler \& Kugler, 2005) }\end{array}$ \\
\hline $\begin{array}{l}\text { Calidad (diferenciación) } \\
\text { (Agarwal y Gort, 1999) }\end{array}$ & $\begin{array}{l}\text { Movilidad } \\
\text { (Segarra \& Teruel, 2007) }\end{array}$ & $\begin{array}{l}\text { Tasa de desempleo } \\
\text { (Audretsch \& Mahmood, 1994) }\end{array}$ \\
\hline \multirow[t]{2}{*}{$\begin{array}{l}\text { Productividad } \\
\text { (Eslava et al, 2005) }\end{array}$} & $\begin{array}{l}\text { Localización } \\
\text { (Arias \& Quiroga, 2008) }\end{array}$ & $\begin{array}{l}\text { Factores institucionales } \\
\text { (Geroski et al., 2003, 2007) }\end{array}$ \\
\hline & $\begin{array}{l}\text { Costos de insumos } \\
\text { (Eslava et al, 2005) }\end{array}$ & $\begin{array}{l}\text { Reformas de mercado } \\
\text { (Eslava et al, 2005) }\end{array}$ \\
\hline
\end{tabular}

Las variables macroeconómicas enunciadas en este estudio, se presentan desde un punto de vista descriptivo, pues se reconoce ampliamente que tales condiciones son importantes en la explicación de la capacidad de sobrevivir de las firmas. Con todo, su estudio no deja de ser una mera descripción del entorno en el que se desarrollaron las firmas durante sus primeros años, de tal forma que no se incluyeron dentro de las estimaciones del modelo probit, ya que su valor no varió entre las firmas sino que fue el mismo para todas las empresas de la muestra.

Dados estos antecedentes y teniendo en cuenta las restricciones para adquirir la información relevan- te, se determinó que las variables a utilizar en las estimaciones del presente artículo corresponden a la rentabilidad, el endeudamiento, el riesgo que manejan, ${ }^{7}$ el tamaño de la firma, el sector económico y la localidad de ubicación en la ciudad.

Con respecto a estas variables incluidas en el modelo econométrico, es preciso señalar algunos hechos estilizados que se observan en ejercicios similares realizados por otros autores. Uno de los hechos más visibles es que el tamaño de una empresa está inversamente relacionado con su probabilidad de cierre en el mercado. El Anexo 2, que exhibe los signos esperados del inventario de variables presen-

6 Elaboración propia.

7 Aunque la variable riesgo no se observó en la revisión de la literatura, su inclusión en las estimaciones responde a ciertos problemas de tipo técnico, que se presentaron al realizar las estimaciones y cuyo origen se explicará cuando se presenten los resultados. 
tadas en la Tabla 1 , revela que en la gran mayoría de estudios, un mayor tamaño de la empresa implica menor probabilidad de cierre ${ }^{8}$. Hay solamente una excepción en la que un mayor tamaño es sinónimo de mayor probabilidad de quiebra (Stone, Hunt \& Holmes, 2010). Al revisar el caso particular, se observa que este resultado fue significativo para la cohorte de microempresas, mientras que para la cohorte de pymes de menor tamaño sí se asocia con menor probabilidad de fracaso. El resultado que obtuvieron estos autores para las microempresas, donde un mayor tamaño se asocia a cierre prematuro, puede ser consecuencia de un cuello de botella inherente a las microempresas. Es decir, siempre que sea microempresa, no importa el tamaño, hay más probabilidad de cierre.

En los casos que estudian la variable rentabilidad, se observa que a medida que ésta aumenta, se presentan más posibilidades de continuar en el mercado. Es preciso mencionar que ninguno de los ejercicios realizados en Colombia -Martínez (2005) ni Arias \& Quiroga (2008)-, fueron aplicados a empresas nuevas sino a empresas con varios años de funcionamiento. Por otra parte, en cuanto a la variable endeudamiento, se observa que el mayor endeudamiento va acompañado de menores posibilidades de continuar en el mercado.

Los autores que se interesaron por estudiar el efecto de indicadores financieros sobre la probabilidad de quiebra, también indagaron por la influencia de la variable liquidez. En el primer caso (Martínez, 2005), con información de Supersociedades, se encuentran los mismos resultados del tamaño y la rentabilidad, de manera que una buena liquidez es conveniente para la continuidad de las firmas en el mercado. En el segundo caso (Arias \& Quiroga, 2008) no encontraron que esta variable sea estadísticamente significativa, por lo que la retiraron de las estimaciones. Como se observará más adelante, en el presente estudio también se experimentan dificultades con la variable liquidez. Posiblemente esta problemática esté asociada con el hecho de que aquí se utiliza la misma fuente de información, que corresponde a la base de datos del registro mercantil de la Cámara de Comercio, aunque en este caso para Bogotá -CCB-, y no para Cali, como en el estudio reseñado. Vale la pena reiterar que entre la literatura revisada para Colombia, no se encontró nada sobre nuevas empresas o -start ups-, como se conocen en la literatura anglosajona. Esto se podría deber a las dificultades para encontrar bases de datos de buena calidad que permitan hacer seguimiento a firmas nuevas.

\section{Estadísticas descriptivas}

Como se mencionó antes, el estudio de la probabilidad de cierre de empresas requiere realizar un análisis, tanto de las condiciones macroeconómicas reinantes en el período, como de los demás factores micro ampliamente discutidos. Las variables macroeconómicas se analizan desde una perspectiva amplia y no se incluyen dentro del modelo econométrico debido a que el valor que toman los datos de $\mathrm{PIB}$, desempleo e inflación, fueron los mismos para todas las empresas de la muestra, con lo que pierde relevancia hacer un análisis para cada firma. Esta caracterización macro y micro se puede dividir en tres grandes secciones: en la primera aparecen las estadísticas macroeconómicas; en segundo lugar se hace un examen detallado de las empresas de la muestra y de la información obtenida en la base de datos; por último, en la tercera sección, se hace una breve descripción de la manera en que se construyeron las variables incluidas en el modelo de respuesta discreta.

\subsection{Entorno macroeconómico en Bogotá 2001-2008}

Los indicadores macroeconómicos entre 2001 y 2006 resultaron alentadores para los empresarios que deseaban iniciar un proyecto empresarial. En estos seis primeros años de la década se observa un crecimiento económico que, aunque intermitente, se puede considerar sostenido, acompañado de descensos en la inflación, el desempleo y en la tasa de interés. No obstante, hacia el final del período

\footnotetext{
8 En otras palabras, tal como está planteado en el Anexo 2, mayor tamaño sinónimo de mayor probabilidad de sobrevivir.
} 
de estudio, dicho entorno favorable se deterioró, al punto de presentarse una desaceleración considerable en el crecimiento económico y un cambio drástico de los otros indicadores que también empezaron a deteriorarse. Este desempeño de los principales indicadores macro de la economía de Bogotá se puede observar en la Ilustración 1.

Vale la pena señalar dos hechos con respecto a los indicadores macroeconómicos presentados. El primero, y tal vez más importante, es que el declive en la economía nacional estuvo marcado, principalmente, por la crisis financiera en Estados Unidos y el deterioro de las relaciones con Venezuela, países que a su vez son los principales socios comerciales de Colombia. El segundo hecho a resaltar, es que el descenso sostenido en la inflación permitió un comportamiento similar en el tipo de interés -DTF a 90 días. Es bien sabido que la brecha entre estos dos indicadores constituye el costo de oportunidad del efectivo y que representa un incentivo al ahorro frente a la posibilidad que tienen los agentes de retener el dinero.

El desempeño de la economía en la ciudad naturalmente incide sobre la constitución y liquidación de sociedades. Esta incidencia se presenta en la Ilustración 2 , en el que se pueden observar algunas características interesantes acerca del comportamiento de los agentes y la creación de empresas.

En esencia, la llustración 2 se puede dividir en dos períodos, el primero entre 2001 y 2003, y el segundo de 2005 a 2007. En el primer período se observó un comportamiento extraño; contrario a lo esperado, en años de mayor crecimiento del PIB aumentó la tasa de liquidación de sociedades y disminuyó la constitución de las mismas. De la misma manera, en los años en los que el crecimiento no fue el mejor, se revirtió la tendencia, aumentó la constitución de empresas y disminuyó la liquidación. Al calcular el coeficiente de correlación (-0.9) se encuentra, desde el punto de vista estadístico, que la relación inversa en estos tres años fue bastante fuerte. Con respecto a este contraste en materia de crecimiento económico y constitución y liquidación de empresas, puede ser consecuencia de una sobrerreacción de los agentes, quienes al venir de un ambiente económico enrarecido por la crisis de la economía colombiana en 1999, reaccionaban exageradamente ante un leve asomo de desaceleración.

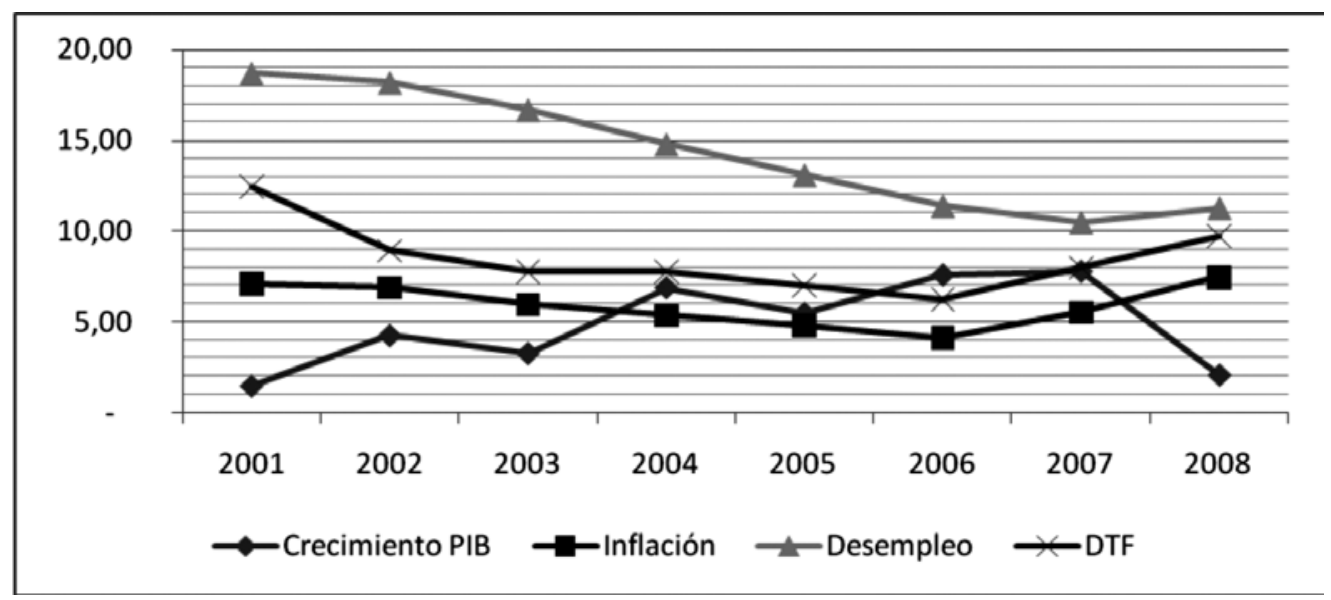

Ilustración 1. Indicadores económicos en Bogotá (2001-2008)9

9 Elaboración propia con base en cifras del Banco de la República y la Secretaría de Hacienda de Bogotá. 


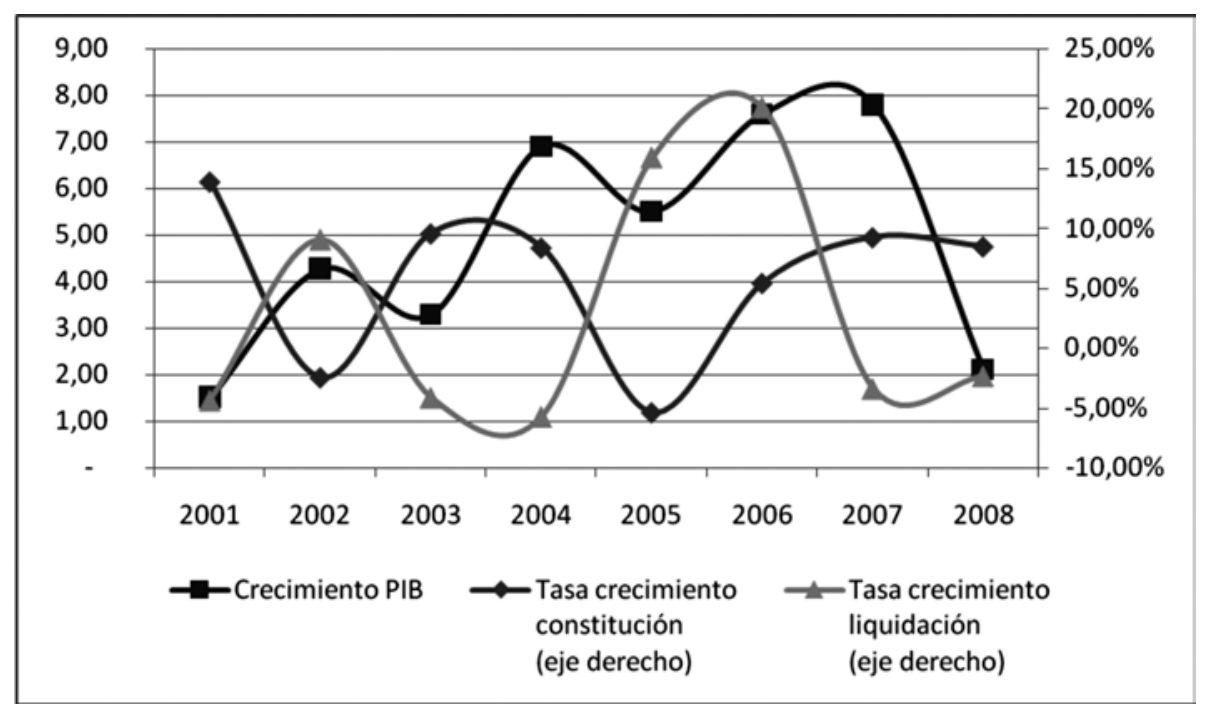

Ilustración 2. Constitución y liquidación de sociedades y su relación con el crecimiento del PIB en Bogotá10

En el segundo período sí se da la relación esperada, años de mayor crecimiento en el PIB se asocian con años de crecimiento en la constitución de empresas y viceversa. Aunque de 2005 a 2006, creció el PIB y creció la liquidación de empresas, la tasa de crecimiento de las empresas constituidas es mucho más considerable que la de liquidación. Estadísticamente, el coeficiente de correlación entre crecimiento del PIB y la tasa de constitución de empresas es positivo (0.98), lo que a diferencia del período anterior, corrobora la relación directa en este período. ${ }^{11}$

Desde el punto de vista macroeconómico estos resultados podrían dar lugar a algunas hipótesis como la presencia de algún rezago en la toma de decisiones, pues cuando la economía crecía, la constitución de empresas no se reactivaba inmediatamente sino que lo hacía hasta el año siguiente. También se podría hablar de una especie de síndrome postcrisis, puesto que los primeros años de la presente década tenían, como antecedente, una de las peores crisis de la economía nacional, la que se presen- tó en 1999. Así, se podría pensar que, ante señales de disminución en el crecimiento económico, los agentes ajustaban sus expectativas de manera que no crecía la constitución de empresas hasta tanto no se consolidara la tendencia expansionista. Por supuesto que estas hipótesis hasta ahora no son robustas, pero es una semilla que resulta de un estudio somero de los datos y que podría dar lugar a un problema de investigación asociado con la teoría macroeconómica de los ciclos.

El último de los indicadores macro que es susceptible de contrastar con la constitución de empresas es el tipo de cambio, para lo cual se escogió el Índice del Tipo de Cambio Real construido por el Fondo Monetario Internacional ITCR-FMI. Al respecto, no se observa ninguna relación desde el punto de vista Ilustración. Aunque una leve tendencia hacia la revaluación coincide con un crecimiento en el número de empresas constituidas, un coeficiente de correlación bastante pequeño (-0.62) desvirtúa cualquier hipótesis al respecto. Seguramente, la escasa

10 Elaboración propia con base en cifras de la Secretaría de Hacienda de Bogotá y la CCB.

11 El año 2004, parece ser el año de transición o ajuste de las expectativas, pues al incluirse en las estimaciones, disminuye el coeficiente de correlación. El año 2008 tampoco se incluyó porque representó el final del ciclo positivo de la economía y presentó una disminución abrupta en este indicador, lo que pudo resultar sorpresivo para los agentes frente a los anteriores años de crecimiento. 
relación entre el tipo de cambio y la constitución de nuevas empresas sea consecuencia del bajo porcentaje de firmas jóvenes con enfoque hacia el sector externo. Esto, a su vez, podría explicar la ausencia generalizada de esta variable dentro de los estudios sobre el tema alrededor del mundo.

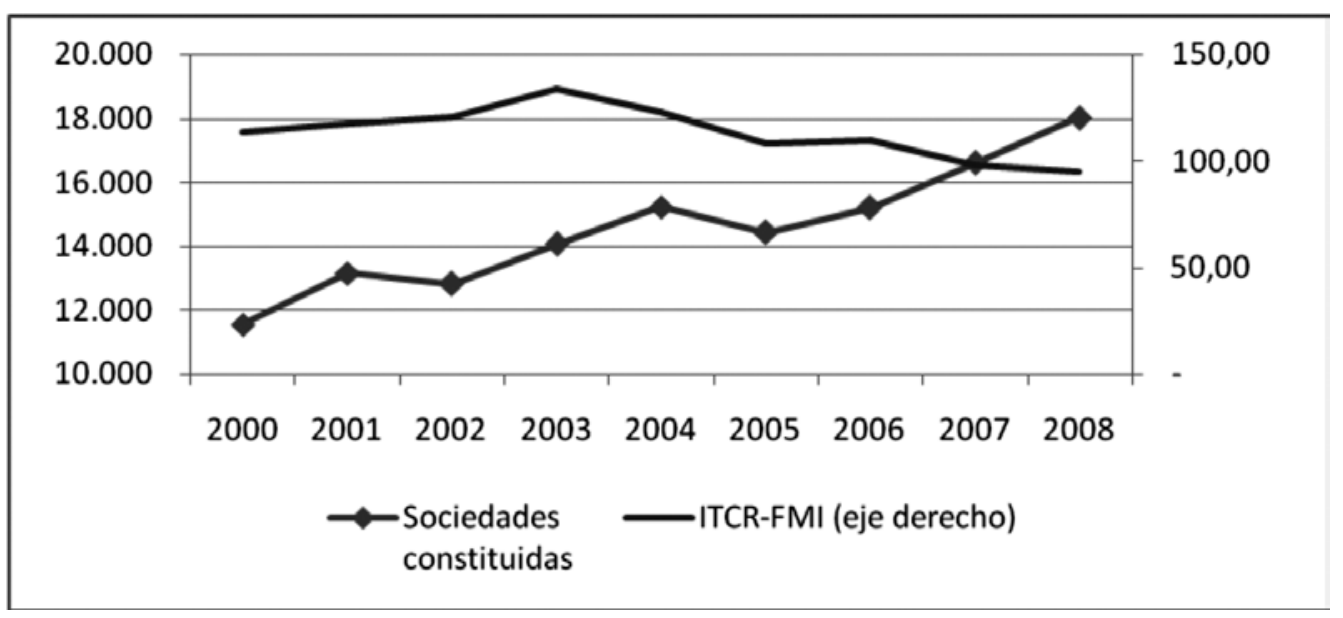

Ilustración 3. Comportamiento del tipo de cambio real y la constitución de empresas ${ }^{12}$

\subsection{Caracterización de las empresas de la muestra}

Dado el panorama macroeconómico favorable, es natural que la tasa de supervivencia de las empresas de la muestra, sea más alta que la de otros estudios aplicados en períodos de mayor turbulencia económica. Algunos estudios tangencialmente relacionados con este, en los que se aplican métodos no paramétricos para medir la sobrevivencia de empresas en la ciudad de Cali ${ }^{13}$ encuentran que, para la década de los 90 y para inicios del presente siglo, la tasa de mortalidad en dicha ciudad fue mucho mayor. No obstante, la explicación al fenómeno que ocurre en Bogotá para firmas creadas entre 2004 y 2005, está relacionada con las condiciones macroeconómicas favorables que se vivieron en los años del período de estudio. Esa estabilidad favoreció la supervivencia de empresas de manera que la tasa de mortalidad sólo alcanzó el $19.46 \%$, lo que se puede considerar bajo en comparación con otros estudios similares tales como el de Arias \& Quiroga $(2008,268)$ que encontraron una mortalidad de $39.8 \%$ para pymes en Cali que tuvieron actividades durante el periodo 2000-2004.

$\mathrm{Al}$ analizar en detalle las condiciones en las que se dio el cese de actividades en las empresas de la muestra, se observa en el Ilustración 5 que, tanto para las que iniciaron en 2004 como para las que lo hicieron en 2005, el tercer año de operaciones fue en el que se cerró un mayor número de firmas. De las 4.147 firmas de la muestra que abrieron sus puertas en 2004, 271 de ellas cancelaron su matrícula mercantil en 2006. Por su parte, de las 4.624 firmas que se matricularon ante el registro mercantil de la Cámara de Comercio de Bogotá en 2005, 299 de ellas se cancelaron en 2007. Ambos casos coinciden en revelar que el tercer año de operaciones presentó el mayor número de cierres para el período estudiado.

12 Elaboración propia con base en cifras de la CCB y el Banco de la República.

13 Arias \& Quiroga (2008) y Martínez (2006). 


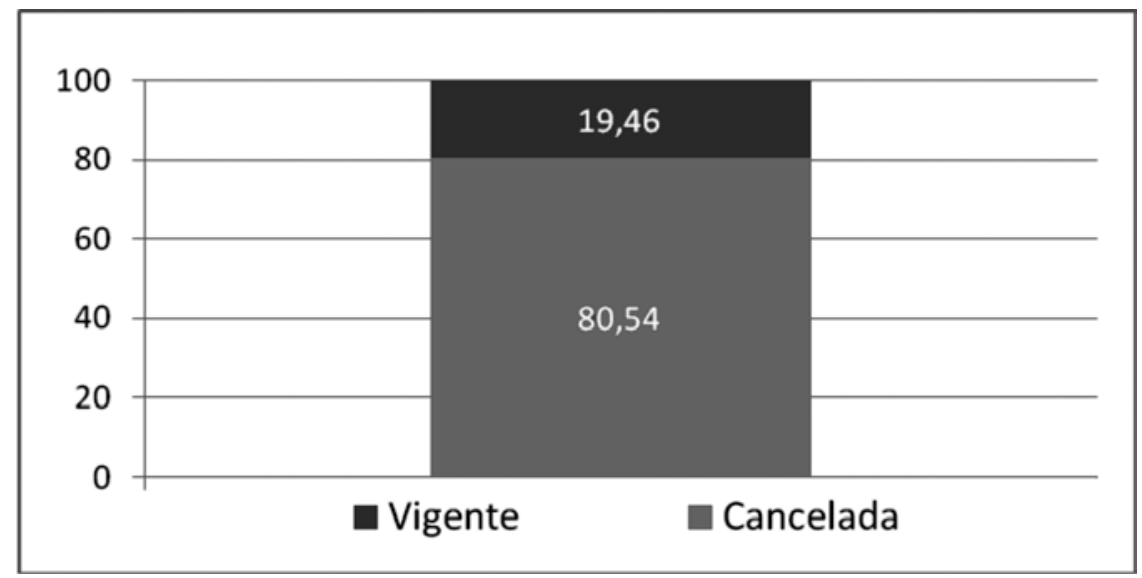

Ilustración 4. Distribución porcentual de firmas creadas entre los años 2004-2005, según estado de la matrícula mercantil en el año $2009^{14}$

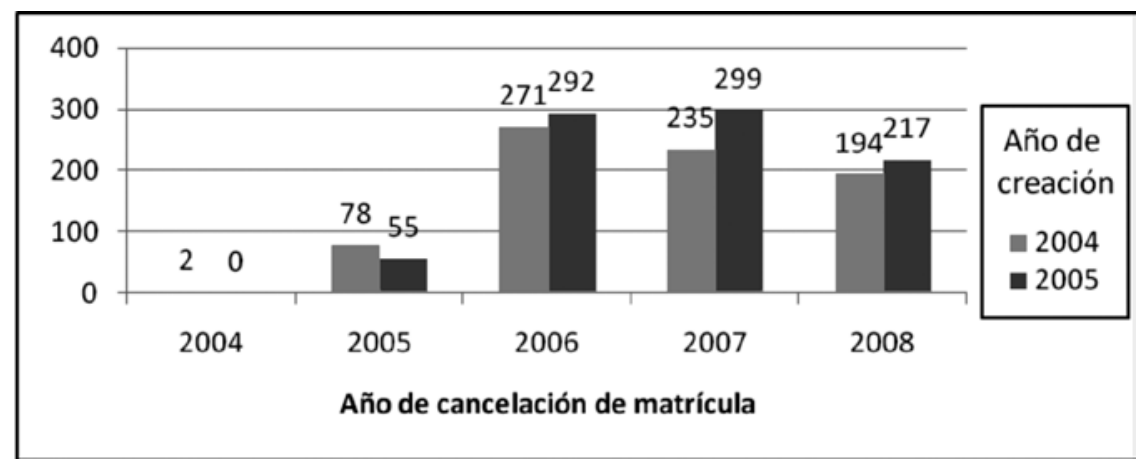

Ilustración 5. Número de empresas que cancelaron matrícula mercantil según año de creación y cierre ${ }^{15}$

Después de observar estas características de las empresas de la muestra, la pregunta que surge es ¿qué diferencia a las empresas que cancelaron su matrícula, de aquellas que lograron sobrevivir? Queda claro que una economía al alza incidió en la baja probabilidad de cierre que experimentaron las empresas de la muestra y que el tercer año de actividades fue en el que se presentó el mayor número de cierres. Ahora lo que interesa analizar es otro tipo de variables micro, entre ellas el tamaño, el sector económico, la localidad de ubicación y las variables financieras. Para ilustrar algunas características de las empresas con respecto a estas variables, se construyó una base de datos que permitiera contrastar si éstas, en efecto, tuvieron algún impacto.

En lo que refiere al tamaño, tal como se observa en el siguiente Ilustración, las empresas de la muestra son en su mayoría microempresas, lo que es un fiel reflejo no sólo de las nuevas firmas sino de la totalidad de las empresas del mercado.

Se observa que el $63.52 \%$ de las nuevas firmas que iniciaron actividades en los años 2004 y 2005, lo hicieron como microempresas. Según la ley, estas son empresas de menos de 10 empleados y/o cuyo

14 Fuente: Elaboración propia con base en cifras de la $\mathrm{CCB}$

15 Fuente: Elaboración propia con base en cifras de la CCB. 
capital es menor a los 500 salarios mínimos mensuales legales vigentes. Con respecto a los sectores económicos en los que se ubicaron estas firmas, la
Tabla 2 presenta la clasificación que usa la Cámara de Comercio de Bogotá, la cual, como ya se señaló, es la fuente de información del presente trabajo.

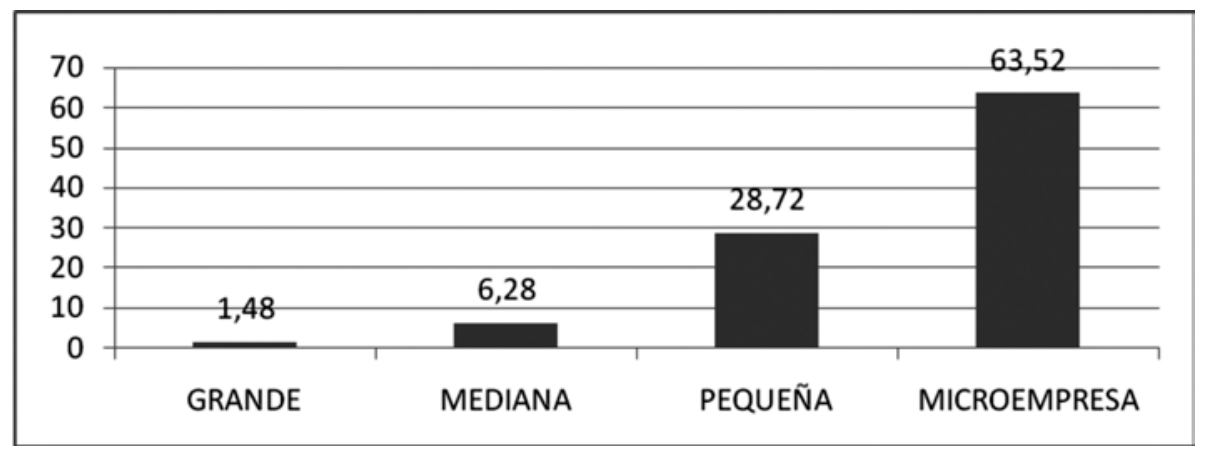

Ilustración 6. Distribución porcentual de nuevas empresas según tamaño. Cohorte 2004-2005¹6.

Tabla 2. Clasificación de sectores económicos de la Cámara de Comercio de Bogotá17

\begin{tabular}{|c|c|}
\hline Código & Descripción Actividad \\
\hline A & Agricultura, ganadería, caza y silvicultura \\
\hline B & Pesca \\
\hline C & Explotación de minas y canteras \\
\hline D & Industrias manufactureras \\
\hline $\mathbf{E}$ & Suministro de electricidad, gas y agua \\
\hline $\mathbf{F}$ & Constructor \\
\hline G & $\begin{array}{l}\text { Comercio al por mayor y al por menor; reparación de vehículos automotores, motocicletas, efectos personales y enseres } \\
\text { domésticos }\end{array}$ \\
\hline $\mathbf{H}$ & Hoteles y restaurantes \\
\hline $\mathbf{I}$ & Transporte, almacenamiento y comunicaciones \\
\hline $\mathbf{J}$ & Intermediación financiera \\
\hline K & Actividades inmobiliarias, empresariales y de alquiler \\
\hline $\mathbf{L}$ & Administración pública y defensa; seguridad social y de afiliación obligatoria \\
\hline M & Educación \\
\hline $\mathbf{N}$ & Servicios sociales y de salud \\
\hline 0 & Otras actividades de servicios comunitarios, sociales y personales \\
\hline $\mathbf{P}$ & Hogares privados con servicio domestico \\
\hline $\mathbf{Q}$ & Organizaciones y órganos extraterritoriales \\
\hline- & Sin dato \\
\hline
\end{tabular}

16 Fuente: Elaboración propia con base en cifras de la CCB.

17 Elaboración propia. 
La distribución porcentual de las nuevas firmas, según los sectores establecidos en dicha clasificación, se puede observar en el Ilustración 7. Esta ilustración revela que 3 de los 17 sectores concentran la mayor cantidad de nuevas firmas. Dichos sectores son: (i) industrias manufactureras; (ii) comercio al por mayor y al por menor, reparación de vehículos automotores, motocicletas, efectos personales y enseres domésticos; y (iii) actividades inmobiliarias, empresariales y de alquiler. Estos tres sectores contienen aproximadamente el 70\% de las nuevas empresas creadas entre 2004 y 2005.
Para terminar con las variables microeconómicas que están asociadas con la organización industrial, se presenta en el siguiente Ilustración la distribución de las nuevas firmas según la localidad en la que se ubicaron. En este Ilustración se observa que la localidad que recibió la mayor cantidad de nuevas empresas fue Chapinero seguida por Usaquén. Diferencias en la tasa de supervivencia entre las empresas que se ubicaron en estas dos localidades y las que se ubicaron en cualquiera de las demás, serán contrastadas de una manera un poco más formal en las estimaciones del modelo probit.

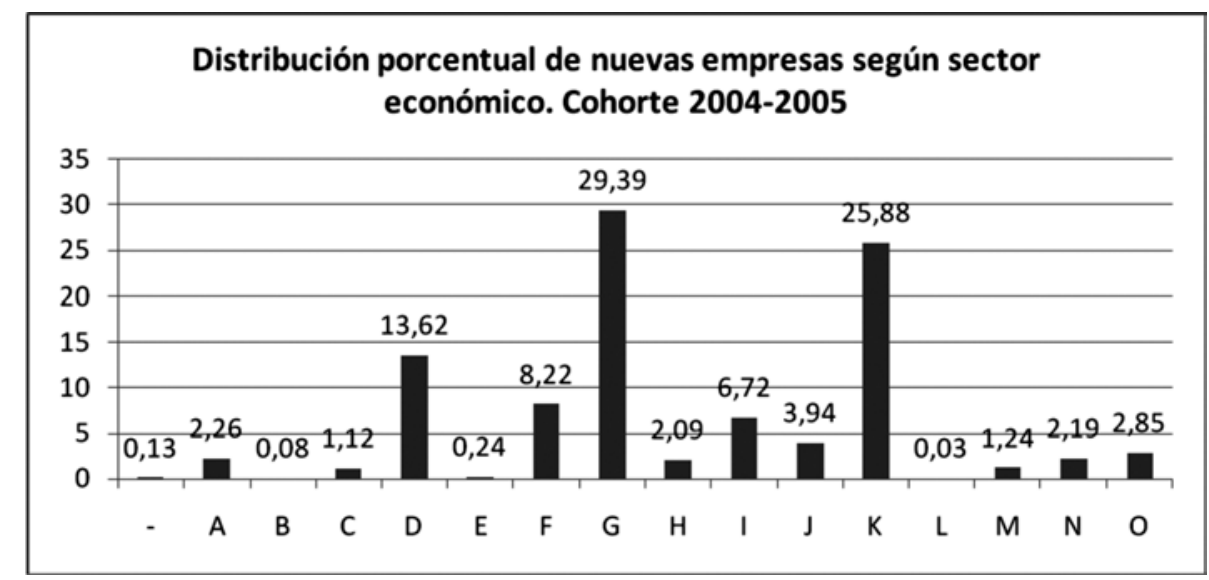

Ilustración 7. Distribución porcentual de nuevas empresas según sector económico. Cohorte 2004-200518

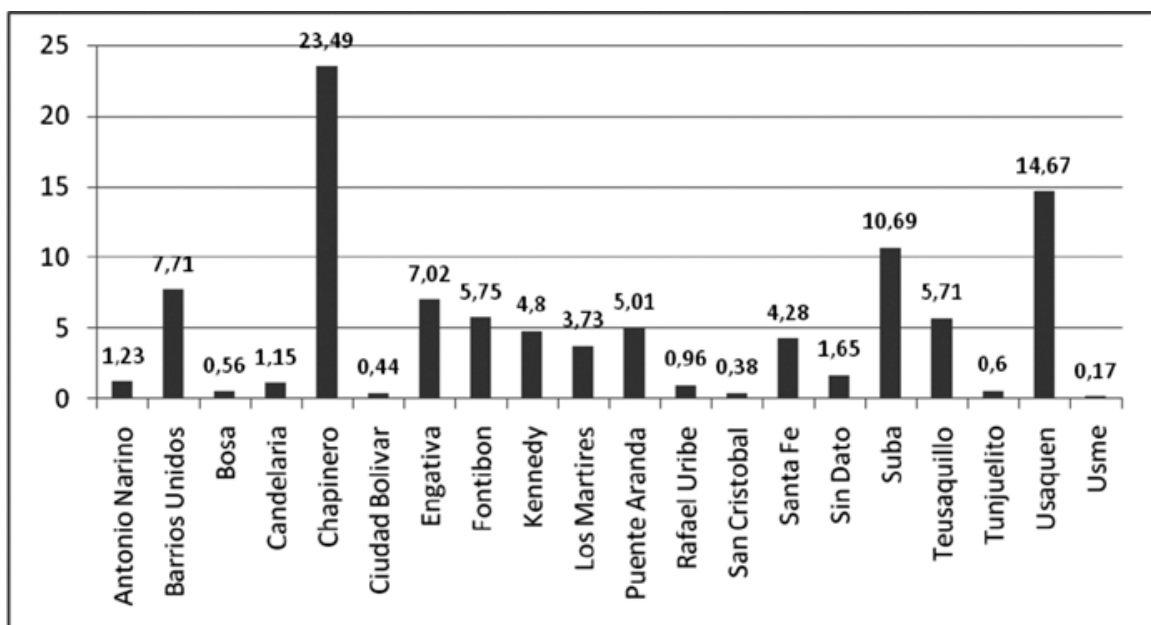

Ilustración 8. Distribución porcentual de nuevas empresas por localidad de ubicación. Cohorte 2004-2005 ${ }^{19}$

18 Fuente: Elaboración propia con base en cifras de la CCB.

19 Fuente: Elaboración propia con base en cifras de la CCB. 
Con estos datos, se pueden resaltar varias características que presentan las empresas tomadas como muestra para el estudio. La primera de ellas es la baja tasa de mortalidad de las empresas del período analizado, en comparación con otros estudios similares; la segunda característica de las empresas de la muestra, que no resulta muy sorpresiva, es que en su mayoría se constituyeron como microempresas; la tercera característica a subrayar está relacionada con el sector económico en el que se ubicaron, donde tres sectores contienen casi el $70 \%$ de las empresas de la muestra. Finalmente, vale la pena añadir que, en cuanto a localidad de ubicación de las nuevas firmas, Chapinero y Usaquén son las que más llamaron la atención de estos nuevos proyectos productivos. De esta manera, a través de las estimaciones se debe verificar la forma en la que las variables tamaño, sector económico y localidad, afectan la sostenibilidad en el tiempo.

\section{Metodología}

\subsection{La construcción de las variables microeconómicas de la firma}

Además de las variables macro y micro que se han caracterizado, se construyeron también indicadores financieros de rentabilidad, endeudamiento y liquidez. Para esto se utilizó la información que reportaron las nuevas firmas a la Cámara de Comercio de Bogotá-CCB, durante el trámite para renovar anualmente la matrícula mercantil. Con esta información se pudo observar el comportamiento de estos indicadores a lo largo de los años subsiguientes. La única información que fue susceptible de conseguir fue la comprendida en los cinco primeros años de existencia de aquellas firmas que iniciaron operaciones entre los años 2004 y 2005. No fue posible conseguir la información financiera durante un período de tiempo mayor, ya que la $\mathrm{CCB}$ no cuenta con una serie de datos más larga. Esta es la razón por la cual se escogió el umbral de los primeros cinco años para realizar el ejercicio. Tampoco se escogieron firmas que hubieran iniciado operaciones recientemente dado que se requiere tener un horizonte de tiempo lo suficientemente largo.
En total la base de datos cuenta con 8.771 firmas con información financiera anual desde que iniciaron actividades, ya sea 2004 ó 2005, hasta su cierre o, en caso de continuar en el mercado, hasta la información reportada en 2009. Este número de nuevas empresas corresponde sólo a sociedades constituidas como anónimas, limitadas, comandita por acciones y comandita simple. Las sociedades unipersonales se eliminaron por ser consideradas refugio del desempleo más que verdaderos ejes de emprendimiento. De la misma manera se eliminaron de la base, las empresas asociativas de trabajo ya que tampoco tienen la condición de emprendimiento y no son creadoras de empleo sino intermediarias del mercado laboral.

Con esta base de datos se procedió a construir las variables financieras que se presentan en la Tabla 3. En ella aparecen diversas razones de rentabilidad como ROA (por su nombre en inglés, Return on Assets) y ROE (por su nombre en inglés, Return on Equity), y la manera en que se construyeron las variables endeudamiento y riesgo. Las variables $\mathrm{ROA}$, ROE y endeudamiento fueron construidas de la manera convencional. Se calcularon esos indicadores para cada año del período de estudio y se obtuvo el promedio. A pesar de que se construyó el indicador para la variable de liquidez, ésta no se tuvo en cuenta debido a que se pierden muchas observaciones pues la gran mayoría de firmas no reportó la información necesaria para su construcción.

En cuanto a la variable riesgo se generó de acuerdo con la metodología VaR (por su nombre en inglés, Value at Risk). Esta metodología calcula el valor de riesgo a través de una aproximación no paramétrica, es decir, que no supone ninguna distribución específica para los retornos de los activos sino que, a través de los retornos históricos, toma el percentil empírico de la distribución muestral. Con esto, el valor de riesgo - VaR-, se calculó como el percentil 5\% de los datos históricos del ROA. De manera alternativa se hubiera podido utilizar la desviación estándar para medir el riesgo; sin embargo, esto implicaría que se podría incluir dentro de la estimación los valores positivos que toma el ROA. Esta alternativa se desestimó ya que lo que se pretende es evaluar la posibilidad de que la empresa obtenga 
rendimientos que se ubican en el 5\% más pequeño, es decir rendimientos que aumentan la posibilidad de cierre de las firmas.

Con la construcción de estas variables financieras, la muestra se dividió en grupos de acuerdo con el promedio que alcanzó cada firma en materia de rentabilidad, endeudamiento ${ }^{20}$ y riesgo; así, se agruparon las firmas según alta rentabilidad, media rentabilidad, baja rentabilidad o rentabilidad negativa; en cuanto a la variable endeudamiento, la clasificación fue entre firmas de alto, medio-alto, medio y bajo endeudamiento. Por último en materia de riesgo, se clasificaron en alto, medio y bajo riesgo; en este último caso el segmento de medio riesgo correspon- de a los cuartiles dos y tres, es decir, los dos grupos de la mitad.

Para las estimaciones se construyeron variables dummy -Tabla 4-, que toman el valor de 1 en caso de presentar la característica, ó 0 en el caso contrario. En esta tabla, al igual que en la presentación de los resultados, se incluyen todas las categorías a excepción de una, de manera que dicha categoría omitida constituye el punto de comparación. Con esto, el signo de cada coeficiente que aparece en la Tabla 5 donde se presentarán los resultados, indica la mayor (+) o menor (-) probabilidad de cerrar la firma antes de los 5 años, en comparación con las firmas que presentan la variable que no se incluyó.

Tabla 3. Razones financieras construidas para las estimaciones ${ }^{21}$

\begin{tabular}{|c|c|c|c|}
\hline \multicolumn{2}{|c|}{ Razones de rentabilidad } \\
\hline ROA & ROE & Endeudamiento & Riesgo \\
\hline$\frac{\text { Utilidad operativa }}{\text { Activos totales }}$ & $\frac{\text { Utilidad operativa }}{\text { Patrimonio líquido }}$ & $\frac{\text { Pasivo total }}{\text { Activos totales }}$ & $V^{2}$ \\
\hline
\end{tabular}

Tabla 4. Variables dummy incluidas en el modelo 22

\begin{tabular}{|c|c|c|}
\hline D1 & Grande $=1$ & \multirow{3}{*}{ TAMAÑO } \\
\hline $\mathrm{D} 2$ & Mediana $=1$ & \\
\hline D3 & Pequeña $=1$ & \\
\hline D4 & Alta rentabilidad $=1$ & \multirow{3}{*}{ RENTABILIDAD } \\
\hline D5 & Media rentabilidad $=1$ & \\
\hline D6 & Baja rentabilidad $=1$ & \\
\hline D7 & Alto riesgo $=1$ & \multirow{2}{*}{ RIESGO } \\
\hline D8 & Medio riesgo $=1$ & \\
\hline D9 & Alto endeudamiento $=1$ & \multirow{3}{*}{ ENDEUDAMIENTC } \\
\hline D10 & Medio-alto endeudamiento $=1$ & \\
\hline D11 & Medio endeudamiento $=1$ & \\
\hline D12 & Ubicación en Chapinero o Usaquén=1 & LOCALIZACIÓN \\
\hline D13 & Sector económico D, G ó K=1 & SECTOR \\
\hline
\end{tabular}

20 Elaboración propia.

21 Este ejercicio es similar al que realizan Arias \& Quiroga (2008) en su artículo sobre cese de pymes en Cali.

22 Elaboración propia. 
De esta forma, las probabilidades se van a comparar con empresas con las siguientes características: en el caso del tamaño el punto de comparación serán las microempresas; en materia de rentabilidad, la comparación será con las firmas que presentan rentabilidad negativa; en lo que a riesgo refiere, serán las firmas con bajo riesgo las que permitan comparar los resultados; en cuanto a endeudamiento lo serán las firmas con bajo endeudamiento; también se compara el efecto de estar en una de las localidades más pobladas como Chapinero o Usaquén, frente a ubicarse en cualquiera de las restantes de la ciudad de Bogotá D.C.; y por último, se trata de dar algún indicio con respecto a la diferencia en cuanto al sector económico en el que opera la nueva firma.

\subsection{El modelo probit}

Dados los resultados de la revisión de la literatura y la disponibilidad de la información, se escogieron las variables dummy presentadas en la Tabla 4 para el análisis de los factores que explican el cierre de firmas nuevas en el mercado. Con dicha información se procedió a la estimación del modelo econométrico para encontrar las probabilidades asociadas a cada variable.

Se escogió el modelo probit ${ }^{23}$ porque cuenta con una serie de ventajas para este tipo de análisis frente a otros modelos similares. Entre las ventajas más relevantes aparece su flexibilidad para incluir nuevas variables de acuerdo con los intereses de investigación. Esta flexibilidad no la ofrece el análisis discriminante propuesto por Altman $(1968)^{24}$ ya que en este sólo se incluyen razones financieras para predecir la quiebra. Por otra parte, entre los modelos de la econometría convencional, el modelo lineal de probabilidad que se estima a través de mínimos cuadrados ordinarios presenta ciertas dificultades que se explican detalladamente en el texto de Wooldridge (2001). Una de ellas, quizá la más documentada en la literatura, es que al realizar las estimaciones, la probabilidad ajustada podría estar por fuera del rango entre 0 y 1 , lo que constituye una contradicción con el mismo concepto de probabilidad.
Los problemas de las metodologías antes planteadas se pueden resolver a través de la estimación con modelos de respuesta binaria como el probit. Este tipo de modelos permiten el estudio de variables cualitativas con técnicas estadísticas apropiadas. Los modelos de respuesta binaria o de variables discretas se utilizan cuando los valores que pueden tomar las variables están comprendidos dentro de un número finito de opciones.

De esta manera se asignan códigos a las cualidades para transformarlas en cantidades susceptibles de medir a través de técnicas econométricas. Estos modelos han sido ampliamente estudiados en la literatura y se reconoce su buen comportamiento al momento de predecir la probabilidad de que ocurra un evento.

El modelo probit presenta una variable endógena (Y) que sólo tiene dos resultados posibles, 0 ó 1. En este caso, 0 equivale a que la nueva empresa sobrevivió a los primeros 5 años de operaciones, mientras que 1 corresponde a que la empresa cerró sus puertas antes de completar el primer lustro. El modelo también cuenta con un vector de variables explicativas $\mathrm{X}$, que para este caso son las variables definidas anteriormente en la Tabla 4. Dadas estas especificaciones, el modelo toma la siguiente forma:

$$
\operatorname{Pr}(\mathrm{Y}=1 \mid \mathrm{X})=\Phi\left(\mathrm{X}^{\prime} \beta\right)(1)
$$

En el modelo observado la probabilidad de que $\mathrm{Y}$ tome el valor de uno, depende de un conjunto de características X, donde $(\Phi)$ es la función de distribución acumulada de la distribución normal estándar, que asume valores que se hallan estrictamente entre 0 y 1.

Los parámetros $\beta$ son estimados mediante un proceso de máxima verosimilitud, sin embargo, su interpretación no es tan directa como la de los parámetros del modelo de mínimos cuadrados ordinarios $^{25}$. De manera más específica, se puede decir que la ecuación que representa el modelo probit a estimar es la siguiente:

23 Un antecedente de la aplicación de esta metodología aparece en (Martínez, 2003).

24 Este análisis discriminante es el mismo aplicado en el artículo Modelo de predicción de quiebras en las empresas colombianas. (Rosillo, 2002).

25 Para detalles acerca de la estimación de los efectos marginales del probit, véase Wooldridge (2001). 
$Y_{i}=\beta O+\beta_{1}$ tamaño $_{i}=\beta_{2}$ localización $_{i}+\beta_{3}$ sector económico $_{i}+$ $\beta_{4}$ rentabilidad $_{i}+\beta$ endedudamiento $_{i}+\beta_{6}$ riesgo $+\varepsilon$

El hecho de cerrar o continuar en el mercado depende, según el modelo aquí construido, de las variables tamaño, localización, sector económico, rentabilidad, endeudamiento y el riesgo que manejen. El signo de los betas asociados a cada una de las variables dummy presentadas anteriormente en la Tabla 5, va a indicar cómo se ve afectada la probabilidad de desaparecer $\left(Y_{i}=1\right)$, es decir, si tener la característica asociada al coeficiente hace que dicha probabilidad se incremente o se disminuya. Nótese nuevamente que las siguientes categorías: microempresas, rentabilidad negativa, bajo riesgo y bajo endeudamiento, no aparecen en la Tabla 4 ni tampoco aparecerán en la Tabla 5 que presenta los resultados.

Esto no significa que no se hayan incluido dentro del modelo sino que, dada la metodología probit, cuando se trabaja con variables dummy es necesario incluir todas a excepción de una de las categorías. Esta variable que no se incluye, permite comparar cuál es la mayor o menor probabilidad de una firma con respecto a esa característica que se omite de manera intencional.

Para garantizar que el modelo fuera robusto a diferentes especificaciones, esto es, que los resultados no fueran sensibles a la forma de medir las variables rentabilidad y endeudamiento, se construyeron 3 alternativas diferentes, que son los modelos 1,2 y 3 que se observarán en la correspondiente Tabla 5 de resultados. La única diferencia entre los modelos 1 y 2 es la forma de medir la rentabilidad ya que el modelo 1 utiliza la utilidad sobre activos -ROA-, en tanto que el modelo 2 mide la rentabilidad a través de la relación entre utilidad y patrimonio $-\mathrm{ROE}$. De la misma manera, el modelo 3 difiere en que la tasa de endeudamiento no se midió con el pasivo total sino con las obligaciones de largo plazo.

Como se presenta en la siguiente sección, los resultados obtenidos con los tres modelos revelan que, cualquiera que sea la forma en que se midan estas variables, los hallazgos apuntan en la misma dirección.

\section{Resultados}

Los resultados de las estimaciones del modelo probit se presentan en la Tabla 5. En ella se puede observar en la parte inferior el porcentaje de firmas que este modelo predice correctamente. Este porcentaje de predicción correcta se presenta para las firmas que cierran (Sensitivity), para las firmas que permanecen (Specificity) y para el total de firmas en promedio. La casilla Total que aparece en la parte inferior de la Tabla 5 indica que, en promedio, el modelo predice correctamente entre el $89 \%$ y el $92 \%$ de las firmas como un todo. Hay que señalar que en todos los modelos estimados, existe mayor poder de predicción para las empresas que no cerraron antes de los 5 años. Esta información aparece al final de la tabla en los valores asociados con Specificity, donde se observa que este poder de predicción estuvo entre el $94 \%$ y el $97.5 \%$. A pesar de esto, el modelo también predice, de manera adecuada, la mayoría de las firmas que cerraron sus puertas antes del primer lustro. En la casilla Sensitivity aparece el porcentaje de este tipo de firmas que el modelo predijo correctamente y se observa que este porcentaje estuvo entre 65\% y 70\%. La casilla PseudoR2 presenta la medida de bondad del ajuste del modelo y la casilla $\mathrm{n}$ corresponde al número de observaciones en la muestra.

En el resto de la Tabla 5 aparecen los resultados de todas las variables incluidas en el modelo. Los efectos de la variable tamaño, por ejemplo, se pueden observar en la parte superior de la tabla, en la primera columna donde aparecen los efectos marginales encontrados para el modelo $1(-0.07,-0.089$ y -0.121). Como se puede observar, los valores son todos negativos, lo que indica que las empresas que tenían alguno de estos tamaños -grande, mediana o pequeña- tienen menos probabilidad de desaparecer frente a las que cuentan con la categoría omitida intencionalmente para facilitar la comparación. En otras palabras, los resultados del modelo 1 permiten afirmar, que las empresas grandes tienen un 7\% menos probabilidad de desaparecer en comparación con las microempresas. De igual forma, las pequeñas y las medianas empresas tienen un $12.1 \%$ y un $8.9 \%$ respectivamente, menos posibilidades de cerrar frente a las microempresas. En consecuencia, se com- 
prueba que son las microempresas las más propensas al cierre prematuro. De la misma manera se puede hacer la lectura de los coeficientes obtenidos para las diferentes categorías de la variable tamaño en los modelos 2 y 3 . Para el resto de variables presentadas en la Tabla 5 se puede hacer el mismo ejercicio de comparar los resultados con la categoría omitida.

Además de comprobarse que las empresas de tamaño pequeño, mediano o grande, presentan menos probabilidad de cerrar frente a las firmas que presentan la categoría de comparación -microempresas-, se observa que las pymes son las que tienen menor probabilidad de desaparecer. Esto podría sugerir, a la luz de los modelos teóricos esbozados en la sección correspondiente, que la estrategia de entrada más eficiente es la que propone el modelo de aprendizaje pasivo (Jovanovic, 1982). En este modelo las nuevas firmas ingresan al mercado con una estrategia conservadora, y de acuerdo con los resultados que obtienen en sus primeros años de actividades, determinan el paso a seguir.

En cuanto a la localidad de ubicación, se realizó un análisis de frecuencias que no permitió inferir que alguna localidad presentara una mayor propensión al cierre en los primeros 5 años. Para este ejercicio se clasificaron las localidades según su alta, media o baja mortalidad. ${ }^{26}$ Los resultados del análisis de regresión no corroboran que las de mayor frecuencia de mortalidad sean estadísticamente significativas en predecir la quiebra. Por esta razón se construyó otra dummy que agrupa sólo a las empresas que se ubicaron en Chapinero o Usaquén. Estas dos localidades sobresalen por ser las de mayor tasa de apertura de nuevas empresas.

Tabla 5. Efectos marginales del modelo probit para predecir la desaparición de nuevas empresas $\left(Y_{i}=1\right)^{27}$

\begin{tabular}{|c|c|c|c|}
\hline & Modelo 1 & Modelo 2 & Modelo 3 \\
\hline \multicolumn{4}{|l|}{ TAMAÑO } \\
\hline Grande & $-0.07^{\star}$ & $-0.086^{\star}$ & $-0.062^{*}$ \\
\hline Mediana & $-0.089^{*}$ & $-0.103^{\star}$ & $-0.092^{*}$ \\
\hline Pequeña & $-0.121^{*}$ & $-0.149^{*}$ & $-0.119^{*}$ \\
\hline \multicolumn{4}{|l|}{$\mathrm{ROA}$} \\
\hline Alta rentabilidad & $0.16^{\star}$ & & $0.139^{*}$ \\
\hline Media rentabilidad & $-0.025^{\star}$ & & $-0.055^{\star}$ \\
\hline Baja rentabilidad & $-0.033^{*}$ & & $-0.054^{*}$ \\
\hline \multicolumn{4}{|l|}{ ROE } \\
\hline Alta rentabilidad & & $0.065^{\star}$ & \\
\hline Media rentabilidad & & $-0.046^{\star}$ & \\
\hline Baja rentabilidad & & 0.025 & \\
\hline \multicolumn{4}{|l|}{ RIESGO } \\
\hline Alto riesgo & $0.154^{*}$ & $0.145^{*}$ & $0.151^{*}$ \\
\hline Medio riesgo & $0.111^{*}$ & 0.047 & $0.087^{* *}$ \\
\hline
\end{tabular}

26 Las localidades que tenían una tasa de mortalidad igual o superior al promedio más una desviación estándar, se denominaron de alta mortalidad. El mismo ejercicio, pero restándole una desviación estándar, se realizó para caracterizar las localidades de baja mortalidad. Las que se ubicaron entre estos dos grupos, todas fueron clasificadas como localidades de mortalidad promedio.

27 Elaboración propia. 


\begin{tabular}{|c|c|c|c|}
\hline \multicolumn{4}{|l|}{ ENDEUDAMIENTO } \\
\hline Alto endeudamiento & $0.228 *$ & $0.293^{*}$ & \\
\hline Medio alto endeudamiento & $-0.031^{*}$ & $-0.03^{*}$ & \\
\hline Medio endeudamiento & $-0.059 *$ & $-0.048^{\star}$ & \\
\hline \multicolumn{4}{|l|}{-Obligaciones de largo plazo } \\
\hline Alto endeudamiento & & & $0.256^{\star}$ \\
\hline Medio endeudamiento & & & -0.019 \\
\hline \multicolumn{4}{|l|}{ ORGANIZACIÓN INDUSTRIAL } \\
\hline Localización en Chapinero o Usaquén & $0.014^{\star *}$ & $0.017^{\star \star}$ & $0.016^{\star *}$ \\
\hline Sector económico D, G ó K & $-0.031^{\star}$ & $-0.032^{*}$ & $-0.027^{\star}$ \\
\hline \multicolumn{4}{|l|}{ Significancia al: * $1 \%-* \star 5 \%-* \star \star 10 \%$} \\
\hline Sensitivity & $68.78 \%$ & $66.90 \%$ & $65.20 \%$ \\
\hline Specificity & $97.45 \%$ & $94.58 \%$ & $97.30 \%$ \\
\hline Total & $91.87 \%$ & $89.19 \%$ & $91.05 \%$ \\
\hline Pseudo R2 & 0.412 & 0.365 & 0.399 \\
\hline$n$ & 8771 & 8771 & 8771 \\
\hline
\end{tabular}

Los resultados reflejan que la dummy construida para aquellas empresas que se ubicaron en alguna de las dos localidades con más densidad empresarial, tienen mayores probabilidades de cerrar. Como se advierte en la sección de la Tabla 5 denominada organización industrial, estas mayores probabilidades están entre el $1.4 \%$ y el $1.7 \%$ que, aunque no es una cifra muy grande, sí resultó estadísticamente significativa. Lo anterior refleja que, al parecer, hay una saturación y la gran competencia parece incrementar la probabilidad de quiebra de las firmas que se ubican allí.

En la misma sección sobre organización industrial, otro de los resultados a resaltar corresponde a los sectores económicos en los que se ubican las nuevas empresas en Bogotá. De acuerdo al análisis econométrico, el modelo probit permite concluir que una firma tiene aproximadamente un 3\% menos probabilidad de cerrar, si se ubica en alguno de los tres sectores económicos en los que ingresaron la mayor cantidad de nuevas firmas. Ellos son: (i) industrias manufactureras; (ii) comercio al por mayor y al por menor, reparación de vehículos automotores, motocicletas, efectos personales y enseres domésticos; y (iii) actividades inmobiliarias, empresariales y de alquiler.
En lo que hace referencia a las variables rentabilidad, endeudamiento y riesgo, que reflejan la salud de las finanzas corporativas de las nuevas firmas, se encuentran algunos resultados sorpresivos. La variable rentabilidad, ya sea analizada a través del indicador ROA o el ROE, indica que las empresas que exhiben baja o media rentabilidad, tienen menor probabilidad de desaparecer que aquellas que presentan una rentabilidad negativa. Por ejemplo, en el modelo 1 , las firmas con rentabilidad media y rentabilidad baja tienen el $2.5 \%$ y el 3.3\% respectivamente, menos probabilidad de desaparecer que las firmas con rentabilidad negativa. Esto coincide con lo encontrado en la literatura, según la cual una rentabilidad negativa se asocia a mayor probabilidad de fracaso. No obstante, surge un resultado muy peculiar al analizar las empresas con alta rentabilidad. En ellas se verifica que existe una mayor probabilidad de cierre que las firmas con rentabilidad negativa.

Contrario a lo que reportan la mayoría de investigaciones, este artículo se enfoca en nuevas firmas cuyas características brindan dos explicaciones sobre este peculiar fenómeno: una es el alto endeudamiento que manejan y la otra es el alto nivel de riesgo. Se corroboró que más de la mitad de las firmas 
que mayor rentabilidad presentan, tienen, a su vez, un alto endeudamiento. Adicionalmente, el efecto marginal del alto endeudamiento sobre la probabilidad de cierre es de 22.8\%, 29.3\% y 25.6\% según el modelo estimado -Tabla 5-. Por otro lado, en lo que corresponde a la alta rentabilidad, estos efectos son $16.5 \%, 6.5 \%$ y $13.9 \%$; también de acuerdo con el modelo que se estime. Esta diferencia en los efectos de una y otra variable, indica que pesa mucho más el hecho de estar altamente endeudado frente a ser altamente rentable.

La segunda hipótesis que surge del análisis de los datos, está relacionada con la variable riesgo. Precisamente, esta fue la razón que llevó a incorporar esta variable a pesar de que no hay antecedentes acerca de su inclusión en este tipo de ejercicios. Los resultados verifican que el resultado sorpresivo con respecto a la alta rentabilidad se da en cualquier caso, es decir, es robusto frente a las diferentes especificaciones o modelos que se manejaron. Para darle sustento a la hipótesis del riesgo, se construyó la variable correspondiente y se estimó el modelo. Los resultados fueron los esperados en cuanto a la relación positiva y directa entre riesgo y probabilidad de cierre. Una firma con alto riesgo tiene, aproximadamente, un 15\% más probabilidades de cerrar frente a una firma con bajo riesgo. Además, se confirmó que las firmas de alta rentabilidad también son las de más alto riesgo, lo que coincide con la teoría financiera. De acuerdo con las estimaciones, más del 60\% de las firmas con alta rentabilidad tienen este problema.

Adicionalmente hay que señalar que también podría influir, aunque en menor medida, la calidad de la base de datos. La información usada es la que reporta cada empresa ante la Cámara de Comercio de Bogotá. Dicha información no es auditada, ni es sujeta a ninguna vigilancia, sino que es completamente discrecional. Por esta razón, es probable que las empresas no reporten de manera verídica la información contable, sino que la variable rentabilidad esté sobreestimada.

Con respecto a la variable endeudamiento, el modelo estimado revela que un alto endeudamiento implica más probabilidades de desaparecer, sin embargo, firmas con endeudamiento medio (-5.9\%) y endeudamiento medio-alto (-3.1\%) tienen menos probabilidad de desaparecer frente a las firmas de bajo endeudamiento. El resultado podría indicar que el endeudamiento moderado, como método para apalancarse es bueno, sin embargo, cuando las deudas son muy altas ponen en riesgo la continuidad de la firma.

De hecho, los resultados de otros autores reflejan estas mismas conclusiones con respecto al endeudamiento (López-García \& Puente, 2006).

\section{Conclusiones}

En general este artículo presenta las características que diferencian las empresas que lograron sobrevivir a los primeros cinco años de actividades, de aquellas que no lo hicieron. En esa medida, ofrece algunas luces, tanto para los emprendedores, como para los encargados de la política de fomento al empresarismo, acerca de la importancia de ciertas variables como el tamaño de la nueva firma, el sector económico al cual se va a incorporar, la localidad de ubicación y otras variables relacionadas con los estados financieros. Otro de los aportes de este artículo es su carácter pionero en el análisis de nuevas empresas a través de ejercicios empíricos como la estimación de un modelo probit.

A pesar de la importancia de conocer las características mencionadas, no se tienen antecedentes en Colombia de la aplicación de este tipo de ejercicios en nuevas empresas.

Así, los hallazgos aquí alcanzados podrían servir para disminuir la probabilidad de fracaso de nuevos proyectos productivos.

Específicamente, se puede señalar que, de acuerdo con los resultados del modelo, el tamaño óptimo de entrada de una empresa, que minimiza la probabilidad de cierre en el mercado durante los primeros cinco años, es el de las pymes, lo que coincide con el modelo de aprendizaje pasivo (Jovanovic, 1982). Además, se corrobora la hipótesis ampliamente aceptada, según la cual, las microempresas son las de mayor probabilidad de desaparecer en los primeros 5 años de vida. 
En materia de finanzas corporativas, las nuevas firmas deben cuidarse de indicadores engañosos con rentabilidades muy elevadas. El estudio de las variables financieras demuestra que a pesar de que una empresa exhiba alta rentabilidad, este buen rendimiento no puede depender de un alto endeudamiento y un alto riesgo, ya que esta mezcla constituye un coctel mortal. Además, la ausencia de endeudamiento no necesariamente indica una baja probabilidad de desaparecer, el crédito hasta cierto punto puede resultar efectivo para que las pymes se apalanquen y de esta manera incrementen su esperanza de vida.

En términos de organización industrial, las estimaciones también arrojan resultados relevantes para los nuevos empresarios. Las dos variables estudiadas, localidad de ubicación y sector económico en el que abrió puertas la nueva firma, resultan estadísticamente significativas y constituyen un elemento a tener en cuenta por parte de los emprendedores. En lo que refiere a localización geográfica, los resultados indican que en las localidades de Chapinero y Usaquén hay más probabilidad de cierre. Por su parte, los sectores económicos en los que hay menor probabilidad de quiebra son aquellos en los que entra un mayor número de nuevas firmas. Estos sectores económicos en los que se observa un menor número de cierres prematuros en nuevas empresas bogotanas son: (i) industrias manufactureras; (ii) comercio al por mayor y al por menor, reparación de vehículos automotores, motocicletas, efectos personales y enseres domésticos; y (iii) actividades inmobiliarias, empresariales y de alquiler.

Aunque los resultados en estas dos variables, localización y sector económico, podrían parecer contradictorios, lo cierto es que no necesariamente las empresas de los sectores económicos en los que se presentan condiciones favorables para la apertura de nuevas firmas están ubicadas en estas localidades. Así, la menor probabilidad de cerrar en los sectores económicos indicados, podría ser resultado de la presencia de algunas economías de escala, hecho que también coincide con lo encontrado en los artículos presentados en la sección sobre modelos teóricos. Específicamente, Jovanovic (1982) señala que, a medida que los mercados maduran, se ex- perimentan rendimientos crecientes. Por su parte, el resultado acerca del mayor riesgo experimentado en zonas como Chapinero y Usaquén, se puede explicar debido a la alta competencia en la zona y el posible menor margen de ganancias que obtienen en su actividad debido, por ejemplo, a la mayor presencia de sustitutos cercanos.

Por último, en lo que se refiere al entorno macroeconómico, a través de estadísticas descriptivas, se identifica un período inicial dentro de la década en el que se observa una sobrerreacción de los agentes frente al deterioro de algunos indicadores macro. Al parecer, durante los primeros años, que estuvieron precedidos por una crisis muy pronunciada, los agentes tomaron decisiones rezagadas, pues los años de mayor crecimiento no coincidieron con los de más constitución de empresas, sino que esto sucedía pasado un año después.

\section{Referencias}

Acts, Z., Armingthon, C., \& Zhang, T. (Diciembre de 2006). The Determinants of New-firm Survival across Regional Economies. Papers on Entrepreneurship, Growth and Public Policy (0407) , 39. Alemania.

Agarwal, R., \& Gort, M. (Abril de 1999). The determinants of firm survival. Obtenido de http://ssrn.com/abstract $=167331$ or DOI: 10.2139/ssrn.167331

Altman, E. (1968). Financial Ratios, Discriminant Analysis and the Prediction of Corporate Bankruptcy. Journal of Finance.

Álvarez, R., \& Vergara, S. (Agosto de 2007). Sobrevivencia de Pymes en Chile: ¿Ha cambiado a través del tiempo?, ¿Difiere por industrias? Recuperado el 17 de Febrero de 2009, de Banco Central de Chile - Documentos de Trabajo: http:// www.bcentral.cl/eng/studies/working-papers/pdf/dtbc427. pdf

Arias, A., \& Quiroga, R. (2008). Cese de actividades de las pymes en el área metropolitana de Cali (2000-2004): Un análisis de supervivencia empresarial. Cuadernos de Administración: 249-277.

Audretsch, D., \& Mahmood, T. (1995). New Firm Survival: New Results Using a Hazard Function. The Review of Economics and Statistics: 97-103.

Buddelmeyer, H., Jensen, P., \& Webster, E. (2006). Innovation and the Determinants of Firm Survival. IZA Discussion Papers. Disponible en: ftp.iza.org/dp2386.pdf

Ericson, R., \& Pakes, A. (1995). Markov-Perfect Industry Dynamics: A Framework for Empirical Works. Review of Economic Studies: 53-82.

Eslava, M., Haltiwanger, J., Kugler, A., \& Kugler, M. (3-4 de Noviembre de 2005). Plant Survival, Market Fundamentals and Trade Liberalization. Recuperado el 21 de Enero de 
2009, dewww.imf.org:http://www.imf.org/external/np/res/seminars/2005/arc/pdf/esla.pdf

Fajnzylber, P., Maloney, W., \& Ribeiro, E. (2001). Firm Entry and Exit, Labor Demand and Trade Reform Evidence from Chile and Colombia. Policy Research Working Paper. Disponible: papers.ssrn.com/so/3/papers.cfm?abstract id $=632727$

Jovanovic, B. (1982). Selection and the Evolution of Industry. Econometrica: 649-670.

López-García, P., \& Puente, S. (2006). Business Demography in Spain: Determinants of Firm Survival. Documentos de Trabajo (0608) . Madrid: Banco de España.

Martínez, A. (2006). Determinantes de la supervivencia de empresas industriales en el área metropolitana de Cali 19942003. En: Revista Sociedad y Economía \#11: 112-144.

Martínez, O. (2003). Determinantes de fragilidad en las empresas colombianas. Borradores de Economía 259. Banco de la República de Colombia.

Mata, J., \& Portugal, P. (1994). Life Duration of New Firms. Journal of Industrial Economics, XLII (3): 227-245.
Mata, J., Geroski, P., \& Portugal, P. (Enero de 2003). Founding Conditions and the Survival of New Firms. Recuperado el 17 de Febrero de 2009, de Banco de Portugal: http://www.bportugal.pt/publish/wp/2003-1.pdf

Mata, J., Geroski, P., \& Portugal, P. (2007). Founding Conditions and the Survival of New Firms. DRUID Working Papers . Disponible en: http://www3.druid.dk/wp/20070011.pdf

Rosillo, J. (2002). Modelo de predicción de quiebras de las empresas colombianas. INNOVAR, No. 19: 109-124.

Schumpeter, J. (1976). Capitalism, Socialism and Democracy. New York: George Allen and Unwin Publishers.

Segarra, A., \& Teruel, M. (2007). Creación y supervivencia de las nuevas empresas en las manufacturas y los servicios. Economía Industrial: 47-58.

Stone, I., Hunt, A., \& Holmes, P. (2010). An Analysis of New Firm Survival using a Hazard Function. Applied Economics: 185195. 


\section{ANEXOS}

\section{Anexo 1. Resultados de algunos de los artículos mencionados en la revisión de la literatura}

\begin{tabular}{|c|c|c|c|c|c|}
\hline Título & Autor-año & Metodología & Determinantes & Signo & Variable independiente \\
\hline \multirow{4}{*}{$\begin{array}{l}\text { Determinantes de fragili- } \\
\text { dad en empresas } \\
\text { colombianas }\end{array}$} & \multirow{4}{*}{$\begin{array}{l}\text { Martínez } \\
\text { (2003) }\end{array}$} & \multirow{4}{*}{ probit } & Rentabilidad & $(-)$ & \multirow{4}{*}{ Estrés financiero } \\
\hline & & & Endeudamiento & $(+)$ & \\
\hline & & & Liquidez & $(-)$ & \\
\hline & & & Dummies por sector económico & & \\
\hline \multirow{8}{*}{$\begin{array}{l}\text { The determinants of } \\
\text { firm survival }\end{array}$} & \multirow{8}{*}{$\begin{array}{l}\text { Agarwal \& } \\
\text { Gort (1999) }\end{array}$} & \multirow{8}{*}{$\begin{array}{l}\text { Cox proportional } \\
\text { hazard }\end{array}$} & Ciclo de vida & $(+)$ & \multirow{8}{*}{ Tasa de Riesgo } \\
\hline & & & mobility of inputs & $(-)$ & \\
\hline & & & tamaño & $(-)$ & \\
\hline & & & diversificación del producto & $(-)$ & \\
\hline & & & Intensidad tecnológica & $(+)$ & \\
\hline & & & bienes de consumo vs prodn & $(-)$ & \\
\hline & & & edad & $(-)$ & \\
\hline & & & edad al cuadrado & $(+)$ & \\
\hline \multirow{4}{*}{$\begin{array}{l}\text { Determinantes de la } \\
\text { supervivencia de em- } \\
\text { presas industriales en } \\
\text { Cali (1994-2003) }\end{array}$} & \multirow{4}{*}{$\begin{array}{l}\text { Martínez } \\
(2006)\end{array}$} & \multirow{4}{*}{$\begin{array}{l}\text { Kaplan-Meier y } \\
\text { Modelos para- } \\
\text { métricos de } \\
\text { duración con } \\
\text { distribuciones } \\
\text { Weibull }\end{array}$} & Ciclo de vida & $(-)$ & \multirow{4}{*}{$\begin{array}{l}\text { Probabilidad de } \\
\text { sobrevivir }\end{array}$} \\
\hline & & & Concentración de la industria & $(+)$ & \\
\hline & & & Tamaño inicial & $(+)$ & \\
\hline & & & crecimiento empresarial & $(+)$ & \\
\hline \multirow{5}{*}{$\begin{array}{l}\text { Cese de actividades } \\
\text { de las pymes en el } \\
\text { área metropolitana de } \\
\text { Cali (2000-2004) Un } \\
\text { análisis de supervivencia } \\
\text { empresarial }\end{array}$} & \multirow{5}{*}{$\begin{array}{l}\text { Arias \& } \\
\text { Quiroga (2008) }\end{array}$} & \multirow{5}{*}{$\begin{array}{l}\text { Cox proportional } \\
\text { hazard y Kaplan- } \\
\text { Meier }\end{array}$} & Tamaño inicial & $(+)$ & \multirow{5}{*}{$\begin{array}{l}\text { Probabilidad } \\
\text { de sobrevivir }\end{array}$} \\
\hline & & & Rentabilidad & $(+)$ & \\
\hline & & & Nivel de endeudamiento & $(-)$ & \\
\hline & & & Crecimiento del sector & $(+)$ & \\
\hline & & & Localización (aglomeración) & $(+)$ & \\
\hline \multirow{5}{*}{$\begin{array}{l}\text { Plant Survival, Market } \\
\text { Fundamentals and } \\
\text { Trade Liberalization }\end{array}$} & \multirow{5}{*}{$\begin{array}{l}\text { Eslava, } \\
\text { Haltiwanger, Ku- } \\
\text { gler \& } \\
\text { Kugler (2005) }\end{array}$} & \multirow{5}{*}{ Probit } & Productividad & $(-)$ & \multirow{5}{*}{$\begin{array}{l}\text { Probabilidad de salir } \\
\text { del mercado }\end{array}$} \\
\hline & & & Demanda & $(-)$ & \\
\hline & & & Costos de los insumos & $(+)$ & \\
\hline & & & Libre comercio & $(+)$ & \\
\hline & & & Reformas orientadas al mercado & $(-)$ & \\
\hline \multirow{11}{*}{$\begin{array}{l}\text { New Firm Survival: } \\
\text { New Results Using a } \\
\text { Hazard Function }\end{array}$} & \multirow{11}{*}{$\begin{array}{l}\text { Audretsch \& } \\
\text { Mahmood } \\
\text { (1995) }\end{array}$} & \multirow{11}{*}{$\begin{array}{l}\text { Cox proportional } \\
\text { hazard }\end{array}$} & Tasa de innovación total & $(+)$ & \multirow{11}{*}{ Tasa de Riesgo } \\
\hline & & & Tasa de innovación firma pequeña & $(-)$ & \\
\hline & & & Tamaño de la firma & $(-)$ & \\
\hline & & & Intensidad del capital (mobility) & $(+)$ & \\
\hline & & & Dummy de propietario & $(+)$ & \\
\hline & & & Tasa de desempleo & $(+)$ & \\
\hline & & & Tasa de interés & $(-)$ & \\
\hline & & & Tasa de crecimiento & $(-)$ & \\
\hline & & & Salarios & $(-)$ & \\
\hline & & & Margen precio-costo & $(+)$ & \\
\hline & & & Concentración mg precio-costo & $(+)$ & \\
\hline
\end{tabular}




\begin{tabular}{|c|c|c|c|c|c|}
\hline \multirow{4}{*}{$\begin{array}{l}\text { Life Duration of New } \\
\text { Firms }\end{array}$} & \multirow{4}{*}{$\begin{array}{l}\text { Mata \& } \\
\text { Portugal (1994) }\end{array}$} & \multirow{4}{*}{$\begin{array}{l}\text { Cox proportional } \\
\text { Hazard }\end{array}$} & Tamaño inicial & $(-)$ & \multirow{4}{*}{ Tasa de Riesgo } \\
\hline & & & Número de plantas & $(-)$ & \\
\hline & & & Crecimiento sectorial & $(-)$ & \\
\hline & & & Tasa de entrada nuevas empresas & $(+)$ & \\
\hline \multirow{8}{*}{$\begin{array}{l}\text { Creación y supervivencia } \\
\text { de las nuevas empresas } \\
\text { en las manufacturas y los } \\
\text { servicios }\end{array}$} & \multirow{8}{*}{$\begin{array}{l}\text { Segarra \& } \\
\text { Teruel (2007) }\end{array}$} & \multirow{8}{*}{$\begin{array}{l}\text { Cox proportional } \\
\text { Hazard }\end{array}$} & Crecimiento sectorial & $(+)$ & \multirow{8}{*}{ Tasa de Riesgo } \\
\hline & & & Intensidad tecnológica (sector) & $(+o ́-)$ & \\
\hline & & & Tamaño inicial (individual) & $(-$ & \\
\hline & & & Movilidad (cohorte) & $(-)$ & \\
\hline & & & Entrantes pequeñas (cohorte) & $(-)$ & \\
\hline & & & Tamaño mínimo eficiente (sector) & $(-)$ & \\
\hline & & & Tasabrutaentradasdec/sector(cohorte) & $(-)$ & \\
\hline & & & Margen precio-costo (sector) & $(-)$ & \\
\hline \multirow[t]{8}{*}{$\begin{array}{l}\text { Creación y supervivencia } \\
\text { de las nuevas empresas } \\
\text { en las manufacturas y los } \\
\text { servicios }\end{array}$} & $\begin{array}{l}\text { Segarra \& } \\
\text { Teruel (2007) }\end{array}$ & $\begin{array}{l}\text { Cox proportional } \\
\text { Hazard }\end{array}$ & Crecimiento sectorial & $(-)$ & Tasa de Riesgo \\
\hline & & & Intensidad tecnológica & $(+)$ & \\
\hline & & & Tamaño inicial (individual) & $(-)$ & \\
\hline & & & Movilidad (cohorte) & $(-)$ & \\
\hline & & & Entrantes pequeñas (cohorte) & $(+)$ & \\
\hline & & & Tamaño mínimo eficiente & $(+)$ & \\
\hline & & & Tasa bruta entradas & $(+)$ & \\
\hline & & & Margen precio-costo & $(-)$ & \\
\hline \multirow{11}{*}{$\begin{array}{l}\text { Sobrevivencia de pymes } \\
\text { en Chile ¿Ha cambiado a } \\
\text { través del tiempo?, ¿Di- } \\
\text { fiere por industrias? }\end{array}$} & $\begin{array}{l}\text { Álvarez \& } \\
\text { Vergara (2007) }\end{array}$ & Probit & Libre comercio & $(+)$ & Probabilidad de sobrevivir \\
\hline & & & Productividad & $(+)$ & \\
\hline & & & capital físico & $(+)$ & \\
\hline & & & tasa salarios no pn/total salarios & (NA) & \\
\hline & & & Antigüedad & $(+)$ & \\
\hline & & & tamaño & $(+)$ & \\
\hline & & & Herfindahl (concentración) & $(+)$ & \\
\hline & & & Mediana empleo sector & (NA) & \\
\hline & & & Publicidad/ventas & (NA) & \\
\hline & & & Crecimiento sectorial & $(+)$ & \\
\hline & & & Dummies por sector económico & (NA) & \\
\hline \multirow[t]{3}{*}{$\begin{array}{l}\text { Founding Conditions } \\
\text { and the Survival of New } \\
\text { Firms (Dinamarca) }\end{array}$} & $\begin{array}{l}\text { Mata, Geroski } \\
\text { \& Portugal } \\
(2007) \\
\end{array}$ & $\begin{array}{l}\text { Cox Proportional } \\
\text { Hazard }\end{array}$ & Concentración & $(-)$ & Tasa de Riesgo \\
\hline & & & Tasa de entrada nuevas empresas & $(+)$ & \\
\hline & & & Ambiente macro & $(-)$ & \\
\hline
\end{tabular}




\begin{tabular}{|c|c|c|c|c|c|}
\hline & & & Tamaño & $(-)$ & \\
\hline & & & K humano & $(-)$ & \\
\hline \multirow[t]{5}{*}{$\begin{array}{l}\text { Founding Conditions } \\
\text { and the Survival of New } \\
\text { Firms (Portugal) }\end{array}$} & $\begin{array}{l}\text { Mata, Geroski } \\
\text { \& Portugal } \\
(2003)\end{array}$ & $\begin{array}{l}\text { Cox Proportional } \\
\text { Hazard }\end{array}$ & Concentración & $(-)$ & Tasa de Riesgo \\
\hline & & & Tasa de entrada nuevas empresas & $(+)$ & \\
\hline & & & Ambiente macro & $(-)$ & \\
\hline & & & Tamaño & $(-)$ & \\
\hline & & & K humano & $(-)$ & \\
\hline \multirow[t]{5}{*}{$\begin{array}{l}\text { Firm entry and exit, labour } \\
\text { demand and trade reform } \\
\text { Evidence from Chile and } \\
\text { Colombia }\end{array}$} & $\begin{array}{l}\text { Fajnzylber, } \\
\text { Maloney \& } \\
\text { Ribeiro (2001) }\end{array}$ & Probit & Tasa de cambio real & $(-)$ & $\begin{array}{l}\text { Probabilidad de no ser ex- } \\
\text { portador el siguiente año }\end{array}$ \\
\hline & & & Tasa de aranceles & $(-)$ & \\
\hline & & & Ssalarios (firma e industria) & $(+)$ & \\
\hline & & & Penetración Importaciones & $(\mathrm{NA})$ & \\
\hline & & & Coeficiente de exportaciones & $(\mathrm{NA})$ & \\
\hline
\end{tabular}

NA: No aplica por no ser significativa.

FUENTE: Elaboración propia. 
Anexo 2. Signos esperados de la probabilidad de sobrevivir

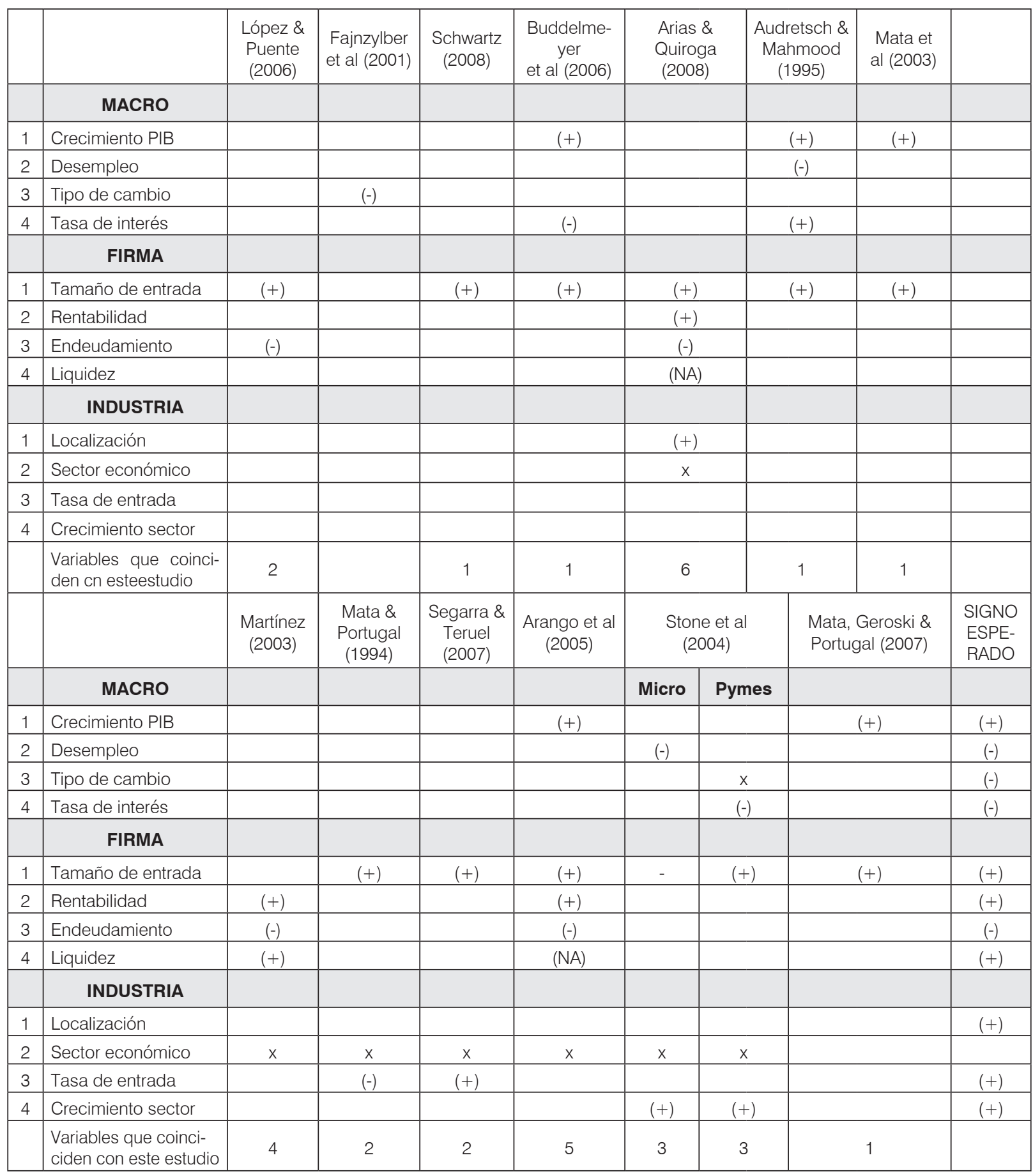

NA: No aplica por no ser significativa.

FUENTE: Elaboración propia 
Anexo 3. Información utilizada para las gráficas

\begin{tabular}{|l|c|c|c|c|c|c|c|}
\hline & Constituidas & Liquidadas & $\begin{array}{c}\text { Crecimiento } \\
\text { PIB Bogotá }\end{array}$ & $\begin{array}{c}\text { Inflación } \\
\text { Bogotá }\end{array}$ & $\begin{array}{c}\text { Desempleo } \\
\text { Bogotá }\end{array}$ & $\begin{array}{c}\text { ITCR FMI } \\
\text { DTF Promedio } \\
\text { Aritmético }\end{array}$ \\
\hline 2000 & 11,550 & 2,831 & 3.69 & & 17.40 & $11,394.00$ & 12.15 \\
\hline 2001 & 13,155 & 2,708 & 1.50 & 7.11 & 18.70 & $11,739.00$ & 12.44 \\
\hline 2002 & 12,832 & 2,953 & 4.27 & 6.93 & 18.20 & 120.54 & 8.94 \\
\hline 2003 & 14,060 & 2,831 & 3.29 & 5.98 & 16.70 & 133.95 & 7.80 \\
\hline 2004 & 15,238 & 2,669 & 6.90 & 5.38 & 14.80 & 122.73 & 7.80 \\
\hline 2005 & 14,418 & 3,093 & 5.50 & 4.84 & 13.10 & 107.89 & 7.01 \\
\hline 2006 & 15,201 & 3,713 & 7.60 & 4.13 & 11.40 & 109.85 & 6.27 \\
\hline 2007 & 16,607 & 3,587 & 7.80 & 5.57 & 10.50 & 98.31 & 8.01 \\
\hline 2008 & 18,015 & 3,503 & 2.10 & 7.49 & 11.30 & 94.80 & 9.74 \\
\hline
\end{tabular}

FUENTE: Elaboración propia con base en cifras de la CCB, el Banco de la República y la Secretaría de Hacienda de Bogotá. 